\title{
El régimen jurídico de la obtención y utilización de muestras biológicas humanas con fines de investigación biomédica en el ordenamiento jurídico español
}

\author{
Sergio Romeo Malanda \\ Profesor Ayudante Doctor de Derecho Penal \\ Universidad de las Palmas de Gran Canaria
}

Recibido: 13.04 .2011

Aceptado: 31.05 .2011

\begin{abstract}
Resumen: La Ley 14/2007 de 3 de Julio, de investigación biomédica (LIB), reconoce que la investigación biomédica y las ciencias de la salud son instrumentos esenciales para mejorar la calidad y la esperanza de vida de las personas, y para incrementar su bienestar. De forma específica enfatiza que la obtención, el uso y la cesión de muestras biológicas con fines diagnósticos y de investigación ha aumentado de forma significativa, y que han surgido incertidumbres éticas y jurídicas que han de ser debidamente reguladas.

La LIB ha pretendido responder a los retos que la investigación biomédica plantea en general y particularmente en relación con las muestras biológicas humanas, a la vez que pretende garantizar la protección de los derechos de las personas que podrían verse vulnerados.

En este artículo, el autor analiza los aspectos legales relativos a la obtención, uso y cesión de muestras biológicas en investigación biomédica. Lógicamente, el marco jurídico pivota en torno al consentimiento del sujeto fuente y en la información que debe haber sido proporcionada previamente a este respecto. Admitiendo que existe una divergencia entre la concesión de consentimientos completamente genéricos y específicos sobre el destino posterior de las muestras, la Ley ha optado por una opción intermedia y flexible.
\end{abstract}

Palabras clave: materiales biológicos humanos, investigación biomédica, consentimiento informado, estudios de diversidad genética, Comités de Ética de la Investigación

Abstract: The Law 14/2007 of 3 July on Biomedical Research (LBR) acknowledges that biomedical research and health sciences are key tools to improve the quality of life and life expectancy of people and increasing their well being. Specifically, it emphasises that the collection, use and transfer of biological samples for diagnostic and research purposes has increased significantly, and that ethical and legal uncertainties have been created that have to be properly regulated.

The LBR has attempted to respond to the challenges that biomedical research raises in general and particularly in relation to human biological samples, and at the same time guarantee the protection of the rights of individuals who could be affected.

In this article, the author analyses the legal aspects related to the collection, use and transfer of biological samples in biomedical research. Logically, the legal framework depends upon the consent of the source of the samples and on the previous information that must be provided in this regard. Recognising that there is a diver- 
gence between the grant of completely generic or specific consent on the use or latter uses of the sample, the Law has chosen an intermediate and flexible option.

Keywords: human biological material, biomedical research, informed consent, Studies of genetic diversity, Research Ethics Committee

Sumario: 1. Introducción: el uso de muestras biológicas con fines de investigación biomédica. 2. Obtención de muestras biológicas. 2.1. Previo: distinción entre el consentimiento para la obtención de una muestra biológica y el consentimiento para su uso posterior. 2.2. Reglas generales relativas a la obtención de muestras biológicas con fines de investigación biomédica. 2.3. Participantes menores de edad y personas incapacitadas. 2.4. Obtención de muestras biológicas de sujetos fallecidos. 2.5. Obtención de muestras biológicas de embriones y fetos humanos. 3. Utilización de las muestras biológicas. 3.1. Empleo para los fines consentidos por el sujeto fuente o su representante legal. Consentimiento para el uso de las muestras biológicas con fines de investigación biomédica. 3.1.1. Muestras biológicas recogidas para un proyecto de investigación específico. 3.1.2. Muestras biológicas recogidas con una finalidad distinta a la investigación que también desean emplearse con fines de investigación. 3.1.2.1. La finalidad secundaria de investigación es conocida en el momento de la obtención. 3.1.2.2. La finalidad secundaria de investigación es sobrevenida. 3.1.3. Revocación del consentimiento para el uso de la muestra biológica. Efectos sobre la muestra. 3.2. El uso de muestras biológicas para fines diferentes a los autorizados por el sujeto fuente. 3.3. Circulación internacional de muestras biológicas. 4. El tratamiento de muestras biológicas en estudios de diversidad genética

\section{Introducción: el uso de muestras biológicas con fines de investigación biomédica}

A lo largo de la historia se ha profesado un respeto muy especial por el cuerpo humano. Respeto que se ha extendido a las partes del cuerpo humano separadas del mismo.

Este respeto mostrado al cuerpo humano no ha sido visto, sin embargo, como una barrera que impida de forma absoluta una utilización diversa del cuerpo humano y sus partes. Así, desde antiguo se viene aceptando la disección de cadáveres donados y su utilización en la formación de estudiantes de medicina. Igualmente, sangre, tejidos y órganos de donantes vivos o fallecidos se emplean para trasplante a fin de salvar, o mejorar la calidad de vida de otros; tejidos humanos se utilizan en investigación científica y médica, lo cual puede conducir al desarrollo de productos terapéuticos que puedan suponer un beneficio para las personas.

De este modo, en pocos años ha cobrado enorme relevancia la obtención, utilización, almacenaje y cesión de las muestras biológicas con fines de in- 
vestigación biomédica. Si bien es indudable que la investigación biomédica en ciencias de la salud es un instrumento clave para mejorar la calidad y la expectativa de vida de los ciudadanos y para aumentar su bienestar, sin embargo, estos avances científicos y los procedimientos y herramientas utilizados para alcanzarlos, generan importantes incertidumbres éticas y jurídicas que deben ser convenientemente reguladas, con el equilibrio y la prudencia que exige un tema tan complejo que afecta de manera tan directa a la identidad del ser humano.

Desde hace varios años han venido apareciendo un gran número de documentos de diferente naturaleza (normas legales, guías éticas, protocolos de actuación, recomendaciones, etc.) elaborados por diversos organismos nacionales e internacionales, los cuales indudablemente han servido de ayuda a los investigadores que utilizan material biológico humano, si bien también han puesto de manifiesto la diversidad de criterios existentes sobre estas cuestiones y la falta de consenso al respecto ${ }^{1}$. Ante este panorama se hace im-

\footnotetext{
${ }^{1}$ Sin ánimo de exhaustividad, entre el ingente número de documentos nacionales e internacionales referentes al tratamiento de materiales biológicos en investigación biomédica, podemos citar los siguientes: Alemania (German National Ethics Council, Biobanks for Research, 2004), Australia (Australian Law Reform Commission, Essentially Yours: The Protection of Human Genetic Information in Australia, 2003), Consejo de Europa (Recommendation Rec (2006) 4 on research on biological materials of human origin, 2006), España (COMité de BioÉtica de CaTaluña, Problemas éticos en el almacenamiento y la utilización de muestras biológicas; GRUPO PARA El UsO DE MuESTRAs BIOLÓGICAS PARA INVESTIGACIÓN BIOMÉDICA, Guía práctica para la utilización de muestras biológicas en investigación biomédica, 2006; COMITÉ DE ÉTICA DEL INSTITUTO DE INVESTIGACIÓN DE ENFERMEDADES RARAS, Recomendaciones sobre los aspectos éticos de las colecciones de muestras y bancos de materiales humanos con fines de investigación biomédica, 2007), Estados Unidos (NATIONAL BIOETHICS ADVISORY COMMISSION, Research involving human biological materials: ethical issues and policy guidance, 2000), Estonia (Human Genes Research Act, 2003), Francia (French National Consultative Ethics Committee, Ethical issues raised by collections of biological material and associated information data : "biobanks", "biolibraries", 2003; Código de Sanidad, tras las reformas introducidas por la Ley de Bioética, 2004), Grecia (NATIONAL BIOETHICS COMMISSION, Recommendation on banks of biological material of human origin (biobanks) in biomedical research, 2006), Irlanda (IRISH COUNCIL FOR BIOETHICS, Recommendations on the collection, use and storage of human biological material in research, 2005), Islandia (Act on a Health Sector Database, 1998; Act on Biobanks, 2000), Italia (ITALian Society Of Human Genetics, Guidelines for Genetic Biobanks, 2004), Organización Mundial de la Salud (World Health Organization, Genetic databases. Assesing the benefits and the impact on human patient rights, 2003), Noruega (Act relating on Biobanks, 2003), Reino Unido (Nuffield CouncIL ON Bioethics, Human tissue. Ethical and Legal issues, 1995; NufFIELD COUNCIL ON BIOETHICS, Human tissue and biological samples for use in research, 2001; MEDICAL RESEARCH COUNCIL, Human Tissue and biological samples for use in research. Operational and ethical guidelines, 2001), Sociedad Europea de Genética Humana (EuROPEAN SOCIETY of Human GenETICS, Recommedations on data storage and DNA banking for biomedical research: technical, social and ethical issues, 2001), Suecia (Law on biobanks in the field of health and medical care, 2002, reformada en 2005), Orga-
} 
prescindible disponer de un marco normativo adecuado que proporcione seguridad jurídica y dé respuesta a los nuevos retos científicos, al mismo tiempo que garantice la protección de los derechos de las personas que pudiesen resultar afectados por la acción investigadora. Además, es necesaria una armonización a nivel internacional de los requisitos para el tratamiento de muestras biológicas en investigación biomédica (consentimiento, confidencialidad, calidad de las muestras, etc.) ${ }^{2}$, pues sólo de esta forma va a poder conseguirse una colaboración fluida entre investigadores de diferentes países.

El legislador español ha venido regulando de forma sectorial el uso de materiales biológicos, atendiendo a la naturalerza de material de que se trata o al fin al que está destinado. Así, existe una detallada normativa sobre el uso terapéutico de órganos, tejidos y sangre ${ }^{3}$, el empleo de gametos con fines reproductivos y de investigación ${ }^{4}$, el uso de material biológico en el curso de una

nización del Genoma Humano (Hugo Ethics Committee, Statement DNA-Sampling: Control and Access, 1997), UNESCO (Declaración internacional sobre los datos genéticos humanos, 2003), Unión Europea (EuROPEAN Group on ETHICs IN SCIENCE AND New TECHNOLOGIES, Opinion on ethical aspects of human tissue banking, 1998).

Vid. también una completa exposición y análisis de diversos documentos normativos y no normativos existentes al respecto, especialmente en el ámbito europeo, Béatrice GODARD/Jörg SCHMIDTKE/Jean-Jacques CASsiman/Ségolène AymÉ, "Data storage and DNA banking for biomedical research: informed consent, confidentiality, quality issues, ownership, return of benefits. A profesional perspective", European Journal of Human Genetics, n' 11 (2003), pp. 88 y ss.

${ }^{2}$ Cfr. Sven Ove Hansson, "The ethics of biobanks", Cambridge Quarterly of Healthcare Ethics, n 13 (2004), p. 324; Jane KAYE, "Do we need a uniform regulatory system for biobanks across Europe?", European Journal of Human Genetics, n ${ }^{\circ} 14$ (2006), p. 245 (sobre la forma más adecuada de abordar esta armonización en el ámbito europeo, vid. p. 247). Indudablemente, documentos tales como la Declaración internacional de la UNESCO sobre los datos genéticos humanos (2003), o la Recomendación del Consejo de Europa sobre investigación con materiales biológicos de origen humano (2006), van esta dirección. Sin embargo, no hay que olvidar que estos documentos no tienen carácter vinculante. Ahora bien, también es cierto, como oportunamente señala Don CHALMERS, "Ethical Principles for Research Governance of Biobanks", Journal of International Biotechnology Law, $\mathrm{n}^{\circ} 3$ (2006), p. 225, que «la armonización de la legislación es inevitablemente compleja, mientras que la armonización de principios éticos sobre investigación con humanos es mucho más realista».

${ }^{3}$ Ley 30/1979, de 27 de octubre, sobre extracción y trasplante de órganos; Real Decreto 2070/1999, de 30 de diciembre, por el que se regulan las actividades de obtención y utilización clínica de órganos humanos; Real Decreto 1301/2006, de 10 de noviembre, por el que se establecen las normas de calidad y seguridad para la donación, la obtención, la evaluación, el procesamiento, la preservación, el almacenamiento y la distribución de células y tejidos humanos y se aprueban las normas de coordinación y funcionamiento para su uso en humanos; Real Decreto 1088/2005, de 16 de septiembre, por el que se establecen los requisitos técnicos y condiciones mínimas de la hemodonación y de los centros y servicios de transfusión. También debe tenerse en cuenta la Ley 29/2006, de 26 de julio, de garantías y uso racional de los medicamentos y productos sanitario, en lo que respecta a los medicamentos de origen humano.

${ }^{4}$ Ley 14/2006, de 26 de mayo, sobre técnicas de reproducción humana asistida. 
autopsia $^{5}$, la obtención y uso de muestras biológicas en el curso de una investigación penal ${ }^{6}$, la importación y exportación de muestras biológicas con fines diagnósticos y de investigación in vivo ${ }^{7}$, o el uso de materiales biológicos con fines de investigación en seres humano ${ }^{8}$. Además, existen otras normas que pueden ser de aplicación cuando se obtenga material biológico de una persona ${ }^{9}$.

Faltaba por regular, sin embargo, otros ámbitos en los que el uso de muestras biológicas ha demostrado ser de una notable relevancia, como es el caso del uso de muestras biológicas ex vivo en investigación biomédica, lo cual ha venido siendo criticado por la doctrina ${ }^{10}$. La Ley 14/2007, de 3 de julio, de Investigación Biomédica (LIB), ha venido a rellenar esta laguna, si bien no regula la materia en toda su extensión, pues en su disposición final tercera se hace referencia al necesario desarrollo reglamentario de alguna de las materias en ella contenidas ${ }^{11}$. Igualmente, las Comunidades Autónomas podrán dictar ciertas disposiciones en el ámbito de las compentencias que les han

${ }^{5}$ Ley 29/1980, de 21 de junio, de Autopsias Clínicas y Real Decreto 2230/1982, de 18 de junio, de desarrollo de la Ley 21 de junio de 1980, reguladora de las Autopsias Clínicas, en el caso de las autopsias clínicas; y Ley de Enjuiciamiento Criminal (art. 343), en el caso de las autopsias forenses o judiciales.

${ }^{6}$ Ley de Enjuiciamiento Criminal (arts. 326.III y 363.II) y Ley Orgánica 10/2007, de 8 de octubre, reguladora de la base de datos policial sobre identificadores obtenidos a partir de ADN (Disposición Adicional Tercera).

${ }^{7}$ Real Decreto 65/2006, de 30 de enero, por el que se establecen requisitos para la importación y exportación de muestras biológicas.

${ }^{8}$ Decreto 1301/2006 y Real Decreto 223/2004, de 6 de febrero, por el que se regulan los ensayos clínicos con medicamentos.

${ }^{9}$ Por ejemplo, el Convenio del Consejo de Europa, de 4 de abril de 1997, sobre Derechos Humanos y Biomedicina o la Ley 41/2002, de 14 de noviembre, básica reguladora de la autonomía del paciente y de derechos y obligaciones en materia de información y documentación clínica.

${ }^{10}$ Así, por ejemplo, Carlos María Romeo Casabona, "Utilización de muestras biológicas y bancos para la investigación biomédica", IV Congreso Mundial de Bioética. Ponencias y comunicaciones, Sociedad Internacional de Bioética, Gijón, 2005, p. 85, afirma que "la carencia actual de prescripciones jurídicas constituyen un vacío normativo que debería subsanarse lo antes posible". En el mismo sentido, Pilar Nicolás JiménEZ, La protección jurídica de los datos genéticos de carácter personal, Cátedra Interuniversitaria de Derecho y Genoma Humano-Comares, Bilbao-Granada, 2006, p. 336.

${ }^{11}$ Según esta Disposición final tercera: "Se faculta al Gobierno para dictar cuantas disposiciones resulten necesarias para el desarrollo y ejecución de esta ley, y en particular para establecer: a) Las normas de intercambio y circulación, interna, intracomunitaria y extracomunitaria, de material biológico de origen humano con fines de investigación; b) Los requisitos de acreditación y autorización de los centros, servicios y equipos biomédicos relativos a la obtención y utilización de cualquier material biológico de origen humano con fines de investigación biomédica; (...) d) el funcionamiento y organización del Registro Nacional de Biobancos para Investigación Biomédica, el cual estará adscrito al Ministerio de Sanidad y Consumo". 
sido atribuidas. Por el contrario, esta norma no será de aplicación a aquellas investigaciones que precisen muestras biológicas, pero que no se desarrollen en el ámbito de la biomedicina, como puede ser el caso de la investigación militar (por ejemplo, para desarrollar armas biológicas) ${ }^{12}$.

Así, en su art. 1, la LIB recoge como objeto de la misma, "regular, con pleno respeto a la dignidad e identidad humanas y a los derechos inherentes a la persona, la investigación biomédica y, en particular: (...) c) El tratamiento de muestras biológicas; d) El almacenamiento y movimiento de muestras biológicas ${ }^{13}$; e) Los biobancos". Sin embargo, a pesar de la amplitud del ámbito de aplicación que subyace en este precepto, lo cierto es que, en realidad únicamente se ocupa del tratamiento de muestras biológicas con fines de investigación biomédica.

En concreto, la cuestión de las muestras biológicas y los biobancos se regula de forma específica en el Título V, y en particular en los Capítulos III ("Utilización de muestras biológicas humanas con fines de investigación biomédica", y IV ("Biobancos"). En el art. 44 LIB, que abre el Capítulo I del Título V ("Disposiciones de carácter general") se establece el objeto de este Título V: $1^{\circ}$ Establecer los requisitos que deben cumplir las instituciones y las personas que traten muestras biológicas; $2^{\circ}$ Velar por el correcto empleo de las muestras biológicas para investigación biomédica; $3^{\circ}$ Establecer los requisitos que deben cumplir los biobancos para su creación y funcionamiento; y $4^{\circ}$ Asegurar la gratuidad en todo el proceso de donación, cesión, almacenaje y utilización de muestras biológicas tanto para los sujetos fuente como para los depositantes, sin perjuicio de la compensación de los costes.

Este trabajo se centra en la primera de las cuestiones mencionadas, esto es, el análisis de la normativa relativa a la obtención y utilización de muestras biológicas con fines de investigación biomédica, y viene a completar la investigación iniciada hacia unos años sobre el tratamiento jurídico de los materiales biológicos, investigación que comenzó con el estudio del régimen jurídico de las muestras biológicas con fines diagnósticos y terapéuticos, tra-

${ }^{12}$ Según Yael Bregman-Eschet, "Genetic Databases and Biobanks: Who controls our Genetic Privacy?", Santa Clara Computer and High - Technology Journal, n 23 (2006), p. 13, la mayor colección de sangre y tejidos en los Estados Unidos (y probablemente en el mundo) pertenece a un organismo militar (el Instituto de Patología de las Fuerzas Armadas), y contiene 92 millones de muestras biológicas, las cuales se han ido almacenando desde el año 1864.

${ }^{13}$ Esta referencia al "almacenamiento y movimiento de muestras biológicas" resulta redundante, pues la LIB ya ha establecido como objeto de la misma el "el tratamiento de muestras biológicas". En el art. 3, letra w) LIB se define tratamiento de de muestras biológica como aquellas "operaciones y procedimientos que permitan la obtención, conservación, utilización y cesión de (...) muestras biológicas”. Así pues, el tratamiento es cualquier actuación en la que se vea envuelta una muestra biológica, incluido su almacenamiento y movimiento. 
bajo publicado en esta misma Revista. ${ }^{14}$ Esta línea de investigación se completará próximamente con el análisis del régimen jurídico de los biobancos con fines de investigación biomédica. ${ }^{15}$

\section{Obtención de muestras biológicas}

\subsection{Previo: distinción entre el consentimiento para la obtención de una mues- tra biológica y el consentimiento para su uso posterior}

En este apartado dedicado a la obtención de muestras biológicas únicamente me ocuparé del consentimiento dirigido a la obtención de la muestra biológica del sujeto fuente. Es decir, antes de destinar la muestra al uso pretendido hay que obtenerla. Para ello el sujeto fuente debe, con carácter general, dar su consentimiento, debiendo ser informado de ciertos aspectos. De este modo, como dice ROMEO CASABONA, "el consentimiento debe abarcar entonces una doble vertiente: el acto principal (participar en un ensayo, someterse a una intervención quirúrgica) y el seguro o posible uso de la muestra biológica" 16 .

Por supuesto, la obtención de la muestra no puede desligarse, en la mayoría de los casos, de su uso posterior. La muestra se obtiene para algo en concreto. Y el sujeto fuente debe conocer también dicho destino. Ello no es óbice para que el acto de obtención y los actos de utilización posterior sean dos realidades diferentes que conviene distinguir, pues también son dos los consentimientos que se prestan y dos las informaciones que el sujeto fuente debe recibir, y ello aunque ambos consentimientos se presten conjuntamente y la información se reciba de forma completa en un mismo acto.

Además, también hay que tener en cuenta que en muchas ocasiones, la muestra se obtiene con una finalidad directa, pero se plantea la posibilidad de usos secundarios. En tales casos, el consentimiento para dichos usos está desligado de la obtención de la muestra y se prestará de forma independiente aunque, de nuevo, si tales usos son ya conocidos en el momento de la obtención, el consentimiento para un uso posterior o secundario pueda prestarse conjuntamente con el del fin principal.

En definitiva, el fin principal al cual desea destinarse la muestra biológica es esencial para el otorgamiento del consentimiento, hasta el punto de que de ello de-

${ }^{14}$ Sergio Romeo Malanda, "La utilización de materiales biológicos humanos con fines diagnósticos y terapéuticos", Estudios de Deusto, Vol. 56, n 1 (2008), pp. 161-213.

${ }^{15}$ V. una visión general sobre esta cuestión, Sergio Romeo Malanda, "Biobancos”, en Carlos María Romeo Casabona (Ed.), Enciclopedia de Bioderecho y Bioética. Tomo I, Comares, Granada, 2011, pp 131-146.

${ }^{16}$ Carlos María Romeo Casabona, "Utilización de muestras biológicas y bancos para la investigación biomédica", IV Congreso Mundial de Bioética. Ponencias y comunicaciones, Sociedad Internacional de Bioética, Gijón, 2005, p. 89. 
penderá la validez del mismo, y que la muestra pueda o no obtenerse ${ }^{17}$. Por ello, en este apartado no vamos a centrarnos tanto en los requisitos de información sobre el destino (principal o secundario) de la muestra, sino en el requisito de la capacidad para poder consentir la obtención de la misma, así como en el de la información sobre la extracción y sus efectos sobre la persona. La cuestión relativa a la información sobre los usos posteriores a la obtención será analizada más abajo.

\subsection{Reglas generales relativas a la obtención de muestras biológicas con fines de investigación biomédica}

El art. 1 LIB establece como uno de los objetos de esta norma, "el tratamiento de muestras biológicas" (letra c). El tratamiento incluye la obtención de las mismas ${ }^{18}$. Como regla general, el art. 4.1.I LIB establece que "se respetará la libre autonomía de las personas que puedan participar en una investigación biomédica o que puedan aportar a ella sus muestras biológicas, para lo que será preciso que hayan prestado previamente su consentimiento expreso y escrito una vez recibida la información adecuada". Por su parte, el art. 4.2.I LIB señala que "se otorgará el consentimiento por representación cuando la persona esté incapacitada legalmente o sea menor de edad, siempre y cuando no existan otras alternativas para la investigación". Además, "las personas que participen en una investigación biomédica podrán revocar su consentimiento en cualquier momento, sin perjuicio de las limitaciones que establece esta ley" (art. 4.3 LIB) ${ }^{19}$.

\footnotetext{
${ }^{17}$ Por ejemplo, si se quiere obtener sangre de una persona, el sujeto deberá consentir el acto médico dirigido a la obtención, teniendo en cuenta que se trata de un procedimiento invasivo. Pero para que éste puede llevarse a cabo, es imprescindible conocer cuál va a ser el destino de la sangre tras su extracción. No es lo mismo que ésta vaya a ser empleada en un diagnóstico clínico, que se obtenga para ser donada con fines terapéuticos, o que vaya a ser utilizada con fines de investigación biomédica. En el primer caso habrá que atender a las reglas contenidas en la LAP y la LIB (si se trata de un análisis genético). En el segundo, habrá que aplicar el Real Decreto 1088/2005, de tal modo que la obtención no se podrá llevar a cabo, por ejemplo, si el sujeto es menor de edad. Finalmente, si esa muestra va a ser empleada en una investigación biomédica, antes de tomar la muestra habrá que comprobar que se cumplen las disposiciones de la LIB (por ejemplo, que existe un informe del Comité de Ética de la Investigación correspondiente).

Para el Grupo PARA El Uso de Muestras BiológicAs PARA InVESTIGACIÓn BioméDiCA, Guía práctica para la utilización de muestras biológicas en investigación biomédica, Instituto Roche, Madrid, 2006, p. 40, «si el procedimiento de la obtención de la muestra representara una afectación de la integridad corporal de tal entidad que pudiera poner en peligro la salud del sujeto, no se podría justificar su empleo en aras de la investigación científica, ni tan siquiera con el consentimiento del sujeto, aunque no debe descartarse como finalidad secundaria o residual».

${ }^{18}$ Cfr. art. 3.w) LIB.

${ }^{19}$ Desde un punto de vista contractual, Ana DíAz MARTínez, "Daños causados en la investigación biomédica y la realización de estudios genéticos: conductas y omisiones determinantes de responsabilidad y resarcimiento", Diario La Ley, 19 de septiembre de 2007, p. 3, entiende que este precepto supone la admisibilidad del desistimiento unilateral como forma de extinción.
} 
Por su parte, el art. 58 LIB está dedicado en exclusiva a la obtención de muestras biológicas para investigación biomédica. Según el apartado primero de este precepto, "la obtención de muestras biológicas con fines de investigación biomédica podrá realizarse únicamente cuando se haya obtenido previamente el consentimiento escrito del sujeto fuente y previa información de las consecuencias y los riesgos que pueda suponer tal obtención para su salud. La donación será revocable". Además, de acuerdo con la Disposición final segunda de la LIB, la Ley 41/2002, de 14 de noviembre, básica reguladora de la autonomía del paciente y de derechos y obligaciones en materia de información y documentación clínica (LAP) será de aplicación de forma supletoria en todo aquello no previsto en la presente Ley.

La Ley de Investigación Biomédica, para asegurarse del cumplimiento de todas las garantías exigidas respecto a la participación de personas en una investigación biomédica, antes de dar inicio a la obtención de las muestras biológicas, exige su sometimiento al control de un Comité de Ética de la Investigación. Así, el art. 12.2 LIB dice que "el Comité de Ética de la Investigación correspondiente al centro ejercerá las siguientes funciones: (...) e) Informar, previa evaluación del proyecto de investigación, toda investigación biomédica que implique (...) utilización de muestras biológicas de origen humano, sin perjuicio de otros informes que deban ser emitidos. No podrá autorizarse o desarrollarse el proyecto de investigación sin el previo y preceptivo informe favorable del Comité de Ética de la Investigación". Además, según el art. 62 LIB, "será preciso, en todo caso, el informe favorable del Comité de Ética de la Investigación correspondiente al centro para la obtención y utilización de muestras biológicas para investigación biomédica (...)"20,21.

\footnotetext{
${ }^{20}$ La intervención del Comité de Ética de la Investigación será necesario incluso cuando las muestras que desean utilizarse vayan a ser obtenidas con un fin distinto al de investigación (diagnóstico o terapéutico), pero se pide el consentimiento para que éstas sean empleadas con tal finalidad de forma secundaria. También resulta irrelevante que las muestras biológicas estén o no anonimizadas (cfr. MEDICAL RESEARCH COUNCIL, Human Tissue and biological samples for use in research. Operational and ethical guidelines, 2001, p. 10. Sin embargo, el GERMAn NATIONAL ETHICs Council, Biobanks for Research, 2004, p. 66, considera que la intervención de un comité de ética no debería ser necesaria cuando se trate de muestras biológicas anónimas o anonimizadas).

Para un análisis más detallado del papel de los Comités de Ética de la Investigación en relación con el uso de muestras biológicas en investigación biomédica, vid. GRUPO PARA EL Uso de Muestras Biológicas PaRa Investigación Biomédica, Guía práctica para la utilización de muestras biológicas en investigación biomédica, Instituto Roche, Madrid, 2006, pp. 133 y ss.

${ }^{21}$ Según la Disposición transitoria tercera de la LIB, “los Comités Éticos de Investigación Clínica dejarán de existir a partir del momento en que se constituyan los Comités de Ética de la Investigación. Hasta que dichos Comités se constituyan, los Comités Éticos de Investigación Clínica que estén en funcionamiento en los centros que realicen investigación biomédica, podrán asumir las competencias de aquéllos".
} 
También puede suceder que las muestras biológicas que desean obtenerse con fines de investigación biomédica no vayan a emplearse en una investigación previamente determinada, sino que lo que se pretende es su almacenamiento organizado en un biobanco poblacional. En tales casos, la LIB también requiere la existencia de una evaluación ética de la política del biobanco respecto a la obtención de las muestras biológicas que van a integrarlo. Por un lado, el art. 69.1 LIB estipula que "la obtención de muestras se realizará de acuerdo con lo previsto en el Capítulo III del presente Título", es decir, incluyendo lo dicho anteriormente respecto a la necesidad de una valoración por parte de un Comité de Ética de la Investigación. Pero además, esta exigencia se recoge de forma expresa cuando en el art. 66.1 LIB, relativo a la organización del biobanco, se establece la obligatoriedad de que el biobanco cuente con un Comité de Ética de carácter externo, cuya misión será asistir al responsable del biobanco en sus funciones. Este Comité será el encargado de valorar los criterios de obtención de las muestras biológicas que vayan a formar parte del biobanco.

La LIB exige un consentimiento escrito para la obtención de muestras biológicas con fines de investigación biomédica ${ }^{22}$. Del mismo modo, de acuerdo con lo dispuesto en el art. 4.1.II LIB, la información se proporcionará igualmente por escrito. Ésta deberá comprender la naturaleza, importancia, implicaciones y riesgos de la investigación.

Por otro lado, la obtención del material biológico, especialmente si se requiere un procedimiento invasivo ${ }^{23}$, deberá ser llevada a cabo por personal sanitario cualificado y en un centro que reúna las condiciones de calidad exigidas $^{24}$. En efecto, la obtención de muestras biológicas con fines de investigación biomédica requiere, en ocasiones, la práctica de procedimientos invasivos de la integridad corporal. En estos casos existe indudablemente un cierto riesgo (siquiera mínimo) para la salud de los sujetos participantes. Cuando ello sea así, habrá que atenerse a lo dispuesto en el art. 18 LIB, precepto que se ocupa de las compensaciones por daños y su aseguramiento, y que es de aplicación, según recoge su apartado $1^{\circ}$, a "las personas que hayan sufrido daños como consecuencia de su participación en un proyecto de investigación". Según DíAZ MARTínEZ, «el específico sistema de responsabilidad que el art. 18 de la Ley de investigación biomédica configura sólo es aplicable a los daños corporales causados con procedimientos invasivos utilizados para la obtención de muestras biológicas cedidas con aquellos fines.

${ }^{22}$ Vid. arts. 4.1.I, 45. d) y 58.1 LIB. No obstante, "si el sujeto de la investigación no pudiera escribir, el consentimiento podrá ser prestado por cualquier medio admitido en derecho que permita dejar constancia de su voluntad" (art. 4.1.IV LIB).

${ }^{23}$ Por procedimiento invasivo se entiende "toda intervención realizada con fines de investigación que implique un riesgo físico o psíquico para el sujeto afectado" [art. 3 t) LIB].

${ }^{24}$ European Group on Ethics in Science and New Technologies, Opinion on ethical aspects of human tissue banking, 1998, apartado 2.1. 
Es un riguroso régimen de responsabilidad objetiva, con inversión de la carga de la prueba en materia de nexo causal, limitado temporalmente a los daños sufridos durante la investigación y en el año siguiente a su terminación, acompañado de la obligatoriedad de suscripción de un seguro y de la determinación de los responsables (entre sí de forma solidaria) en caso de que, por distintas causas, el seguro no diera cobertura al siniestro» ${ }^{25}$.

\subsection{Participantes menores de edad y personas incapacitadas}

Según el art. 58.5 LIB "la obtención de muestras biológicas de menores de edad y personas incapacitadas con fines de investigación biomédica, estará sometida a las siguientes condiciones: a) que se adopten las medidas necesarias para garantizar que el riesgo de la intervención sea mínimo para el sujeto fuente; b) que de la investigación se puedan obtener conocimientos relevantes sobre la enfermedad o situación objeto de investigación, de vital importancia para entenderla, paliarla o curarla; c) que estos conocimientos no puedan ser obtenidos de otro modo; y d) que se cuente con la autorización por parte de los representantes legales del menor o de la persona incapacitada o que, en su caso, existan garantías sobre el correcto consentimiento de los sujetos fuente". Estos requisitos no se exigirán si el destino de las muestras biológicas a la investigación está previsto como secundario al fin principal de diagnóstico o tratamiento ${ }^{26}$, salvo que desee aprovecharse tal intervención para obtener una cantidad de material biológico con fines de investigación superior al que sería necesario para poder llevar a cabo el fin principal. En tal caso, la obtención de ese material extraordinario deberá someterse a las reglas establecidas sobre obtención de muestras biológicas con fines de investigación biomédica.

Es el investigador quien debe valorar, en primer lugar, la capacidad real de participante en la investigación. La capacidad individual para consentir

\footnotetext{
${ }^{25}$ Ana DíAz MARTínez, "Daños causados en la investigación biomédica y la realización de estudios genéticos: conductas y omisiones determinantes de responsabilidad y resarcimiento", Diario La Ley, 19 de septiembre de 2007, p. 6 (vid. también, pp. 2 y s.). Esta interpretación tan restrictiva del art. 18 LIB se debería, según esta autora, al hecho de que un precepto legal redactado en la forma en que éste lo está, no puede contener una modificación tan esencial de nuestro sistema de responsabilidad (p. 2).

${ }^{26}$ Los materiales biológicos que han sido obtenidos para fines específicos distintos del de investigación se regirán por la normativa concreta que regule los mismos. Cfr. Carlos María ROMEO CASABONA, "Utilización de muestras biológicas y bancos para la investigación biomédica", IV Congreso Mundial de Bioética. Ponencias y comunicaciones, Sociedad Internacional de Bioética, Gijón, 2005, p. 82; Amelia Martín Uranga/Ma Concepción Martín-Arribas/Jeanne-Hélène di Donato/Manuel PosadA DE la PAZ, Las cuestiones éticojurídicas más relevantes en relación con los biobancos, Instituto de Salud Carlos III-Ministerio de Sanidad y Consumo, Madrid, 2005, p. 11.
} 
debe considerarse en relación con diversas variables. En principio, ésta se presume en sujetos mayores de edad no incapacitados, pero puede negarse en un caso concreto y en un momento determinado. Por ejemplo, algunos sujetos pueden sufrir una falta de capacidad debido a un determinado tratamiento médico en el que se encuentran incursos o a la medicación que están tomando ${ }^{27}$. Igualmente, individuos que padecen ciertos desórdenes, como esquizofrenia, pueden disfrutar de prolongados periodos de lucidez.

La letra d) del art. 58.5 LIB exige "que se cuente con la autorización por parte de los representantes legales del menor o de la persona incapacitada". Si el sujeto no es capaz para tomar decisiones debido a su estado físico o psíquico y carece de representante legal (es decir, se trata de una persona incapaz no incapacitada $)^{28}$, una interpretación a sensu contrario de dicho precepto nos lleva a la conclusión de que no será posible su participación en el proyecto de investigación de que se trate. Es decir, no podrán consentir la obtención de muestras biológicas las personas vinculadas a él por razones familiares o de hecho.

Por otra parte, a diferencia de la normativa sobre ensayos clínicos, la cual exige que éstos sean de interés específico para la población que se investiga y que la investigación deberá guardar relación directa con alguna enfermedad que padezca el menor o el incapaz, o bien ser de naturaleza tal que solo pueda ser realizada en menores ${ }^{29}$, la LIB requiere "que de la investigación se puedan obtener conocimientos relevantes sobre la enfermedad o situación objeto de investigación, de vital importancia para entenderla, paliarla o curarla" [art. 58.5.b)]. La diferencia es clara y sustancial. Mientras que Real Decreto 223/2004 requiere que el sujeto de la investigación padezca una cierta enfermedad o desorden, en la LIB esto no es un requisito esencial, basta con que la participación de un sujeto (que puede estar totalmente sano) pueda ser de gran relevancia para la investigación que va a llevarse a cabo ${ }^{30}$.

Por otro lado, el art. 58.5.d) exige "que se cuente con la autorización por parte de los representantes legales del menor o de la persona incapacitada $o$ que, en su caso, existan garantías sobre el correcto consentimiento de los sujetos fuente" (énfasis añadido). Esa referencia al "correcto consentimiento del sujeto fuente" debe ser entendida en el sentido de que cuando un menor de edad o una persona incapacitada demuestren en el caso concreto capacidad su-

${ }^{27}$ Cfr. IRISH COUNCIL FOR BIOETHICS, Recommendations on the collection, use and storage of human biological material in research (2005), p. 32.

${ }^{28}$ Por ejemplo, cuando se trata de una persona en coma o de ancianos considerados no capaces pero no incapacitados legalmente

${ }^{29}$ Cfr. arts. 4.a) y 5.a) Real Decreto 223/2004.

${ }^{30}$ Esta regulación puede suponer, sin embargo, una limitación importante para obtener muestras biológicas de estos sujetos cuando el fin principal es almacenarlas en ciertos tipos de biobancos. 
ficiente para comprender las razones y efectos de la obtención de la muestra, serán ello y no sus representantes legales quienes deberán prestar el consentimiento. En cualquier caso, cuando ello no sea posible, el sujeto deberá participar en la medida de lo posible en la toma de decisión ${ }^{31}$. Además, si bien en un primer momento son los representantes legales de la persona menor de edad o incapacitada los que consienten la obtención de la muestra biológica, éstos podrán tomar una decisión al respecto tan pronto como adquieran una suficiente capacidad de juicio ${ }^{32}$.

\subsection{Obtención de muestras biológicas de sujetos fallecidos}

Por lo que respecta a la obtención de muestras biológicas de sujetos fallecidos con fines de investigación biomédica, nada dice la LIB al respecto. Sí lo hace, en cambio, la Recomendación del Consejo de Europa 4 (2006), sobre investigación con materiales biológicos de origen humano, según la cual, " 1 . No deberían extraerse materiales biológicos del cuerpo de un individuo fallecido con fines de investigación sin el pertinente consentimiento o autorización. 2. No deberían extraerse o utilizarse materiales biológicos del cuerpo de un individuo fallecido con fines de investigación si consta la oposición del individuo fallecido" (art. 13).

Aunque esta cuestión no se contiene en la LIB, sin embargo sí que podemos encontrar alguna referencia en otra normativa. Así, el art. 5.2 Ley 30/1979, dice que "la extracción de órganos u otras piezas anatómicas de fallecidos podrá realizarse con fines (...) científicos, en el caso de que éstos no hubieran dejado constancia expresa de su oposición"33. Además, en ningún lugar se encuentra una prohibición expresa de ello.

${ }^{31}$ Cfr. arts. 154 del Código civil, 9.3 y 9.5 in fine LAP, 9.1 de la Ley Orgánica 1/1996, de 15 de enero, de Protección Jurídica del Menor.

${ }^{32}$ Cfr. Medical Research Council, Human Tissue and biological samples for use in research. Operational and ethical guidelines, 2001, p. 26.

${ }^{33}$ Aunque esta Ley se refiere a la extracción y trasplante de órganos, se ha venido entendiendo por la doctrina de forma pacífica que lo establecido en la misma es igualmente aplicable a la extracción y trasplante de otros tejidos. O lo que es lo mismo, el término órgano debe entenderse aquí de forma amplia. De hecho, la disposición adicional segunda de esta Ley únicamente excluye de su ámbito de aplicación a la sangre humana y sus derivados, a la vez que establece una previsión particular para la córnea y "otros tejidos".

Cfr. a este respecto, Carlos María Romeo CASABONA, "Los principios jurídicos aplicables a los trasplantes de órganos y tejidos", en Carlos María Romeo Casabona (coord.), El nuevo régimen jurídico de los trasplantes de órganos y tejidos, Comares, Granada, 2005, p. 67; Victor Angoitia Gorostiaga, "Los tejidos y los bancos de tejidos", en Carlos María Romeo Casabona (coord.), El nuevo régimen jurídico de los trasplantes de órganos y tejidos, Comares, Granada, 2005, pp. 251 y s., Daniel García SAN JosÉ, "De vuelta con las células madre: el marco europeo de la clonación humana y los bancos de cordones umbilicales", Revista de Derecho Comunitario Europeo, nº 24 (2006), p. 486, nota 13; David LARIOS RISCO, 
En cualquier caso, corresponderá al Comité de Ética de la Investigación valorar la necesidad y conveniencia de obtener muestras biológicas de individuos fallecidos, así como los requisitos para su obtención (por ejemplo, exigir el consentimiento de sus familiares). El art. 48.2 LIB puede servir de referencia para establecer las pautas de actuación en estos casos. De este modo: a) se podrán obtener y analizar muestras de personas fallecidas siempre que pueda resultar de interés para la investigación biomédica; b) dicha obtención no se llevará a cabo si el fallecido lo hubiera prohibido expresamente en vida y así se acredita. A tal fin serán consultados los documentos de instrucciones previas y, en su defecto, el criterio de los familiares más próximos del fallecido; c) existe valoración positiva de la obtención por parte del Comité de Ética de la investigación correspondiente; d) ha sido autorizado por los familiares más próximos del fallecido ${ }^{34}$; y e) las muestras se utilizarán de forma anonimizada, pues la presunción de donación para investigación

"Donación y uso privativo de la sangre del cordón umbilical: aspectos jurídicos", Derecho y Salud, n 2 (2007), p. 187.

Además, el Real Decreto 1301/2006 expresamente reconoce en su exposición de motivos que para su elaboración se ha tenido en cuenta la Ley 30/1979, y así lo entiende también la LIB cuando en su art. 1.4 dispone que quedan excluidas de su ámbito de aplicación las implantaciones de órganos, tejidos y células de cualquier origen que se regirán por lo establecido en la Ley 30/1979, de 27 de octubre, sobre extracción y trasplante de órganos; y en la Disposición adicional primera, según la cual "la utilización con fines terapéuticos de cualquier material biológico de origen humano a los que hace referencia esta Ley, se regirá, según corresponda por la Ley 30/1979, de 27 de octubre, sobre extracción y trasplante de órganos".

${ }^{34}$ Aunque el marco normativo de referencia se contenga, como hemos dicho, en la Ley 30/1979, y ésta claramente ha optado por un modelo de consentimiento presunto, de tal manera que se entiende que el sujeto fallecido consiente la donación salvo que haya manifestado lo contrario, lo cierto es que en la práctica se procede a solicitar el consentimiento expreso y escrito de la familia del donante. Vid. más ampliamente al respecto, Asier URRUELA Mora, "Trasplante de órganos y tejidos: aspectos jurídicos y sociológicos ligados al consentimiento familiar", en Carlos María Romeo Casabona (coord.), El nuevo régimen jurídico de los trasplantes de órganos y tejidos, Comares, Granada, 2005, pp. 335 y ss. Cfr. igualmente, EuroPean Group on Ethics in Science And New Technologies, Opinion on ethical aspects of human tissue banking, 1998, apartado 2.3.2; COMITÉ DE ÉTICA DEL INSTITUTO DE INVESTIGACIÓN DE ENFERMEDADES RARAS, "Recomendaciones sobre los aspectos éticos de las colecciones de muestras y bancos de materiales humanos con fines de investigación biomédica", Revista Española de Salud Pública, n ${ }^{\circ} 2$ (2007), p. 107.

Además, según el Medical Research Council, Human Tissue and biological samples for use in research. Operational and ethical guidelines, 2001, p. 25, en aquellos casos en los que haya constancia acreditada de la voluntad del fallecido de ceder su material biológico con fines de investigación biomédica, sería oportuno informar de ello a la familia. Es más, también se dice que si ésta muestra serias objeciones a la toma de las muestras, esta postura debería ser respetada, a pesar de los deseos del fallecido.

Por otro lado, en alguna ocasión, podría no ser posible localizar a algún familiar del fallecido. En tal caso, este mismo organismo recomienda no tomar las muestras. 
contenida en el mencionado art. 5.2 Ley 30/1979 únicamente se refiere a la utilización de las muestras, pero no abarca a los datos ${ }^{35}$.

En relación con lo anterior, también hay que tener en cuenta que en cierto tipo de muertes, si ha intervenido una autoridad judicial y se está procediendo a la práctica de una autopsia forense ${ }^{36}$, puede ser necesaria a la autorización del juez para poder obtener o utilizar el material biológico en cuestión ${ }^{37}$.

\subsection{Obtención de muestras biológicas de embriones y fetos humanos}

El Capítulo I del Título III de la LIB (arts. 28 y 29) se ocupa de la donación de embriones y fetos humanos y de sus estructuras biológicas. Según dispone el primero de ellos, podrán ser donados con fines de investigación biomédica u otros fines diagnósticos, terapéuticos, farmacológicos, clínicos o quirúrgicos, los embriones humanos que hayan perdido su capacidad de desarrollo biológico, así como los embriones o fetos humanos muertos. En tales casos, se deberán cumplir los siguientes requisitos (art. 29 LIB):

a) Que el donante o donantes de los embriones o los fetos hayan otorgado previamente su consentimiento de forma expresa y por escrito. Si alguno de aquéllos fuera menor no emancipado o estuviera incapacitado, será necesario además el consentimiento de sus representantes legales.

b) Que el donante o los donantes o, en su caso, sus representantes legales, hayan sido informados por escrito, previamente a que otorguen su consentimiento, de los fines a que puede servir la donación, de las consecuencias de la misma, así como de las intervenciones que se vayan a realizar para extraer células o estructuras embriológicas o fetales, de la placenta o las envolturas, y de los riesgos que pueden derivarse de dichas intervenciones.

c) Que se haya producido la expulsión, espontánea o inducida, en la mujer gestante de dichos embriones o fetos, y no haya sido posible mantener la autonomía vital de los mismos

d) Que la donación y utilización posterior nunca tenga carácter lucrativo o comercial.

En el caso de que hubieren fallecido las personas de las que provienen los embriones o los fetos, será necesario que no conste su oposición expresa.

${ }^{35}$ Grupo para el Uso de Muestras Biológicas para Investigación Biomédica, Guía práctica para la utilización de muestras biológicas en investigación biomédica, Instituto Roche, Madrid, 2006, pp. 40 y 87.

${ }^{36}$ Las autopsias forenses (reguladas en los arts. 343 y 353 de la Ley de Enjuiciamiento Criminal) se requieren en casos de muerte violenta o no natural, repentina e inexplicada. La autopsia se dirige a investigar las causas de la muerte. En algunos casos, es necesario retener órganos completos o grandes porciones de tejidos para realizar un examen detallado.

${ }^{37}$ Cfr. arts. 5.3 Ley 30/1979 y 10.5 RD 2070/1999. 
Si el fallecido fuera menor de edad o una persona incapacitada, la donación tendrá lugar a no ser que conste la oposición expresa de quienes ejercieran, en vida de aquéllos, su representación legal.

\section{Utilización de las muestras biológicas}

\subsection{Empleo para los fines consentidos por el sujeto fuente o su representante} legal. Consentimiento para el uso de las muestras biológicas con fines de investigación biomédica

En este apartado se analiza tanto el consentimiento que debe prestar el sujeto fuente cuando la muestra se ha obtenido con un objetivo directo o principal de investigación, como cuando dicha utilización es secundaria. Es posible que una vez que la muestra ha sido empleada con fines preferentes de diagnóstico o terapéuticos, aún quede material sobrante. Muchas veces ese material será destruido o almacenado si una correcta asistencia sanitaria del paciente así lo requiere. Pero también puede exisitir interés en emplearlo con otros fines. En tal caso, además del consentimiento para el diagnóstico o tratamiento, habrá que consentir también el subsiguiente uso o almacenamiento para fines diversos.

El art. 4.1.I LIB establece que "respetará la libre autonomía de las personas que puedan participar en una investigación biomédica o que puedan aportar a ella sus muestras biológicas, para lo que será preciso que hayan prestado previamente su consentimiento expreso y escrito una vez recibida la información adecuada". De igual manera, en el art. 45 LIB se dice que, "además de las garantías establecidas en el Título I de esta Ley, se aplicarán, los siguientes principios: (...) d) Consentimiento: Deberá obtenerse previamente el consentimiento escrito del sujeto fuente o en su caso de sus representantes legales para el tratamiento de muestras con fines de investigación (...)". Y el art. 60.1 LIB señala que "el consentimiento sobre la utilización de la muestra biológica se otorgará, bien en el acto de obtención de la muestra, bien con posterioridad, de forma específica para una investigación concreta". El consentimiento se otorgará en el acto de obtención de la muestra cuando ésta se obtenga bien con fines de investigación, bien con otros fines pero con la intención de destinar los materiales biológicos sobrantes a la misma. Por su parte, el consentimiento se otorgará con posterioridad, para una investigación concreta, cuando no habiéndose previsto su posible uso en el momento de la obtención con otros fines, ahora desea utilizarse en un proyecto de investigación determinado.

\subsubsection{Muestras biológicas recogidas para un proyecto de investigación espe- cífico}

Cuando la muestra se obtenga directamente con fines de investigación científica, la información se dará y el consentimiento se otorgará antes de obtener la 
muestra $^{38}$. Tanto la información como el consentimiento deberán constar por escrito $^{39}$. No obstante, "si el sujeto de la investigación no pudiera escribir, el consentimiento podrá ser prestado por cualquier medio admitido en derecho que permita dejar constancia de su voluntad" (art. 4.1 IV LIB) ${ }^{40}$. Del mismo modo, si el sujeto en cuestión no sabe o no puede leer (por ejemplo, es analfabeto o ciego), o tiene problemas para entender la información escrita, la información debería proporcionarse por medios adecuados a su condición (audio, video, braille, etc. $)^{41}$. Por supuesto, el consentimiento escrito no sustituye una explicación verbal más detallada de los procedimiento a los participantes en la investigación ${ }^{42}$.

En la actualidad, no cabe duda alguna de que la transmisión de una información adecuada a los sujetos participantes en una investigación biomédica es un requisito esencial para la validez del consentimiento. El objetivo de la información es que los donantes otorguen el consentimiento siendo conscientes de su importancia e implicaciones. Pero ello no se conseguirá si la información es excesiva y demasiado técnica y compleja (lo cual puede producirse cuando ésta va más dirigida a servir de protección al investigador que a facilitar el entendimiento de los sujeto fuente $)^{43}$. El alcance de la infor-

\footnotetext{
${ }^{38}$ No obstante, hay que recordar que este consentimiento es independiente del consentimiento que debe prestarse para el hecho mismo de la extracción, que requerirá de otro tipo de información adicional (por ejemplo, sobre los efectos sobre su salud, o periodos de convalecencia).

${ }^{39}$ Vid. arts. 4.1.I, 45. d), 58.1 y 59 LIB.

${ }^{40} \mathrm{Cfr}$. IRISH COUNCIL FOR BIOETHICS, Recommendations on the collection, use and storage of human biological material in research (2005), p. 40.

${ }^{41}$ Cfr. Medical Research Council, Human Tissue and biological samples for use in research. Operational and ethical guidelines, 2001, p. 16.

${ }^{42}$ Medical Research Council, Human Tissue and biological samples for use in research. Operational and ethical guidelines, 2001, p. 15.

${ }^{43}$ German National Ethics Council, Biobanks for Research, 2004, p. 57. En relación con esta cuestión, algunos estudios recientes constatan que la gente no se toma muy en serio la información que recibe. Incluso aunque tengan algunas dudas sobre la investigación en cuestión, los donantes raramente prestan atención a la hoja de información antes de tomar la decisión de ceder o no la muestra biológica.

A este respecto, Michael BARR, "'I'm not Really read up on Genetics': Biobanks and the Social Context of Informed Consent”, BioSocieties, ${ }^{\circ} 1$ (2006), pp. 258 y ss., afirma que «un gran numero de participantes en una investigación prestan de hecho muy poca atención a los detalles del estudios y aparentemente no les importa en absoluto esa falta de conocimiento. (...) La cuestión es que la gente decide, según parece, atendiendo a sus vivencias personales, necesidades y experiencia. En otras palabras, no parece que la gente toma decisiones debido a detalles tales como los medios utilizados para mantener la información confidencial, los costes del estudio, los colaboradores internacionales del proyecto, o a qué temperatura se mantendrá conservada la placenta». En otro estudio, Klaus HoEYER/Niels LYNÖE, "Motivating donors to genetic research? Anthropological reasons to rethink the role of informed consent", Medicine, Health Care and Philosophy, $\mathrm{n}^{\circ} 9$ (2006), pp. 16 y ss., sostienen que ni aquéllos que han rechazado la donación de las muestras, ni aquéllos que han accedido a ella, dieron una razón vinculada a la hoja de información que hubiera influenciado su decisión. Preguntados entonces sobre la razón por la que habían accedido a ceder las mues-
} 
mación está regulado en el art. 59 LIB. Según este precepto, antes de emitir el consentimiento para la utilización de una muestra biológica con fines de investigación biomédica que no vaya a ser sometida a un proceso de anonimización, el sujeto fuente recibirá la siguiente información:

a) Finalidad de la investigación o línea de investigación para la cual consiente;

b) Beneficios esperados. A este respecto, debe informarse de los beneficios esperados tanto para el sujeto fuente como para la sociedad ${ }^{44}$. Además de ello debe informarse de los posibles beneficios económicos para el investigador que se pueden derivar de la investigación o que esperan conseguirse con la misma ${ }^{45}$. Así pues, los investigadores de-

tras biológicas para investigación, la mayoría de los donantes hablaron en términos muy generales sobre los beneficios para la sociedad y la ciencia, mostrando su confianza en el correcto uso de las mismas por los investigadores.

Este estudio también concluyó que los donantes no prestan atención a la hoja de información porque ésta no se ocupa de las cuestiones que realmente les interesan. Se trata, sin embargo, de cuestiones que difícilmente pueden ser objeto de información. Así, los intereses de los donantes están más vinculados a los problemas sociales y a los usos de la ciencia, tales como si todos los grupos poblacionales van a poder acceder a los resultados de las investigaciones, si éstos serán de utilidad para el conjunto de la población, que los resultados de la investigación no estarán mediatizados por intereses empresariales, así como cuestiones relativas a las aplicaciones eugenésicas del conocimiento científico.

En relación con lo anterior, conviene hacer énfasis, especialmente a raíz de estos estudios, en que el derecho de autoderminación se respeta cuando el sujeto toma la decisión contando con los medios y la información necesaria para que dicho consentimiento pueda ser considerado plenamente informado. Sin embargo, por razones de seguridad jurídica, debe ser irrelevante a este respecto que el sujeto esté de facto realmente informado. Nadie puede acreditar realmente cuál es el conocimiento efectivo que una persona tiene sobre el acto que está consintiendo y sobre el cual ha sido adecuadamente informado. Como dice Michael BARR, "'I'm not Really read up on Genetics': Biobanks and the Social Context of Informed Consent", BioSocieties, $\mathrm{n}^{\circ} 1$ (2006), p. 258, los donantes son capaces de tomar decisiones sin querer o necesitar comprender todos los detalles de un estudio. «Todos nosotros, en uno u otro momento, tomamos decisiones y firmamos formularios sin leer la letra pequeña o ser absolutamente conscientes de aquello a lo que estamos accediendo. (...) Todos nosotros, en uno u otro momento, tomamos decisiones y firmamos formularios sin querer conocer la letra pequeña o ser absolutamente conscientes de aquello a lo que estamos accediendo. Es una elección legítima para un participante en una investigación no querer ser informado» (la cursiva aparece en el original).

${ }^{44}$ Comité de Bioética de Cataluña, Problemas éticos en el almacenamiento y la utilización de muestras biológicas, Barcelona, 2004, pp. 94 y s.

${ }^{45}$ Comité de BioÉtica de CATAluña, Problemas éticos en el almacenamiento y la utilización de muestras biológicas, Barcelona, 2004, pp. 94 y s. La propia LIB, cuando trata el tema de la información que debe transmitirse a los sujetos participantes en investigaciones que implican procedimientos invasivos en seres humanos (Título II), exige informar de "cualquier futuro uso potencial, incluyendo los comerciales, de los resultados de la investigación" [art. 15.2.h)].

En este mismo sentido, Margaret OTLOWSKI, "Ethical Considerations in Genetic Research Involving Commercial Use of Human Tissue", en AA.VV., Regulating Human Genetics, Centre for Law and Genetics, Hobart, 2001, pp. 39 y s.; Amelia MARTín URANGA/Ma Concepción MARTín-ARRIBAs/Jeanne-Hélène Di DonATO/Manuel PosAdA DE LA PAZ, Las cuestiones ético- 
berían discutir con los participantes en la investigación los usos potencialmente comerciales de su material biológicos u obtenidos de la investigación en las que dicho material ha sido empleado. La revelación del las potenciales aplicaciones comerciales está además indicada por las consecuencias prácticas de la investigación, ya que la gente podría desconfiar de los médicos e investigadores, al sentir que han sido engañados y tratados injustamente ${ }^{46}$;

c) Posibles inconvenientes vinculados con la donación y obtención de la muestra, incluida la posibilidad de ser contactado con posterioridad con el fin de recabar nuevos datos u obtener otras muestras ${ }^{47}$;

d) Identidad del responsable de la investigación. También se incluirá la oportuna información de contacto para poder resolver cualquier duda que se plantee ${ }^{48}$

e) Derecho de revocación del consentimiento y los efectos de la misma, incluida la posibilidad de la destrucción o de la anonimización de la muestra. Tales efectos no se extenderán a los datos resultantes de las investigaciones que ya se hayan llevado a cabo;

f) Lugar de realización del análisis y destino de la muestra al término de la investigación: disociación, destrucción, u otras investigaciones, y que en su caso, comportará a su vez el cumplimiento de los requerimientos previstos en esta ley. En el caso de que estos extremos no se co-

jurídicas más relevantes en relación con los biobancos, Instituto de Salud Carlos III-Ministerio de Sanidad y Consumo, Madrid, 2005, p. 63, para quienes "respetar el consentimiento libre e informado del sujeto fuente implica dar una información precisa, especialmente acerca de la eventualidad de una solicitud de patente. Esto significa que el sujeto debe conocer la posibilidad de que a partir de la parte del cuerpo que dona, aunque sea información genética, cabe la posibilidad de desarrollar una patente si se llegara a desarrollar una invención que cumpliera todos los requisitos de patentabilidad (...)". También Carlos María Romeo Casabona, "Utilización de muestras biológicas y bancos para la investigación biomédica", IV Congreso Mundial de Bioética. Ponencias y comunicaciones, Sociedad Internacional de Bioética, Gijón, 2005, p. 89, pide que se informe de «que los resultados de la investigación con muestras biológicas del sujeto podrán dar lugar a algún producto -o procedimiento- patentable».

${ }^{46}$ IRISH COUNCIL FOR BIOETHICS, Recommendations on the collection, use and storage of human biological material in research (2005), Recomendación 13; Dianne NicOL, "Public Trust, Intellectual Property and Human Genetic Databases: The Need to Take Benedit Sharing Seriously", Journal of Internacional Biotechnology Law, $\mathrm{n}^{\mathrm{o}} 3$ (2006), p. 93; Margaret OTLOWSKI, "Donor Perspectives on Issues Associated with Donation of Genetic samples and Information: An Australian Viewpoint", Bioethical Inquiry, n 4 (2007), pp. 136 y s.

${ }^{47}$ Cualquier contacto con los donantes para fines no especificados en este acto de consentimiento, debe entenderse como no incluido en el mismo y exigiría aprobación por parte de un Comité de Ética de la Investigación. Cfr. Medical Research Council, Human Tissue and biological samples for use in research. Operational and ethical guidelines, 2001, p. 14.

${ }^{48}$ Comité de BioÉtica de Cataluña, Problemas éticos en el almacenamiento y la utilización de muestras biológicas, Barcelona, 2004, pp. 94 y s. Además, si se adopta la decisión de trasladar las muestras o el proyecto a una nueva localización, habrá que informar de ello a los participantes, para que puedan ejercer oportunamente sus derechos. 
nozcan en el momento, se establecerá el compromiso de informar sobre ello en cuanto se tenga conocimiento. La LIB opta así por un consentimiento en dos partes ("two-part consent") ${ }^{49}$, de tal modo que el donante es requerido para consentir el proyecto de investigación específico ya previsto, y además debe consentir el uso posterior del material biológico cuando dicho proyecto haya concluido. Por supuesto, el sujeto fuente debe poder negarse a destinar sus muestras biológicas para usos diferentes del proyecto de investigación específico que está consintiendo ${ }^{50}$;

g) Derecho a conocer los datos genéticos que se obtengan a partir del análisis de las muestras donadas;

h) Garantía de confidencialidad de la información obtenida, indicando la identidad de las personas que tendrán acceso a los datos de carácter personal del sujeto fuente. Dado la enorme sensibilidad de la información relativa a la salud, es imprescindible que los investigadores tengan claro desde el comienzo de la investigación el uso que van a dar a los datos obtenidos. Ello incluye la manera en la que la información resultante del estudio será puesta en conocimiento de los participantes ${ }^{51}$, lo cual será igualmente objeto de valoración por el Comité de Ética de la Investigación y comunicado a los participantes junto con el resto de información. Esto es, antes de que se recojan las muestras, tienen que haberse diseñado los mecanismos para asegurar la confidencialidad de la información que se obtenga y la conservación a largo plazo del material biológico;

i) Advertencia sobre la posibilidad de que se obtenga información relativa a su salud derivada de los análisis genéticos que se realicen sobre su muestra biológica, así como sobre su facultad de tomar una posición en relación con su comunicación ${ }^{52}$. Esta es una cuestión muy impor-

${ }^{49}$ Tal y como recomienda el Medical Research Council, Human Tissue and biological samples for use in research. Operational and ethical guidelines, 2001, p. 15.

${ }^{50}$ Medical Research CounCIL, Human Tissue and biological samples for use in research. Operational and ethical guidelines, 2001, p. 16.

${ }^{51}$ IRISH COUNCIL FOR BIOETHICS, Recommendations on the collection, use and storage of human biological material in research (2005), Recommendation 20.

${ }^{52}$ Según Garrath Williams/Doris SchroEDER, "Human Genetic banking: altruism, benefit and consent", New Genetics and Society, $\mathrm{n}^{\circ} 1$ (2004), p. 93, recontactar con el sujeto fuente para informarle de los resultados de un análisis llevado a cabo sobre la muestra biológica que cedió corre el peligro de convertir un proyecto de investigación en un cribado genético, lo cual requiere de una cantidad de trabajo y dinero probablemente inasumible. Sin embargo, para Henry T. GreELY, "The Uneasy Ethical and Legal Underpinning of Large-Scale Genomic Biobanks", Annual Review of Genomics and Human Genetics, $\mathrm{n}^{\circ} 8$ (2007), pp. 359 y s., la comunicación al sujeto fuente de estos descubrimientos que pueden afectar a su salud (o a la de su descendencia) debe ser la regla general, pues ello forma parte del deber de socorro. Sobre este particular, vid. asimismo, Ellen Wright Clayton, "Informed Consent and Biobanks", The Journal of Law, Medicine \& Ethics, no 1 (2005), p. 20; Mark A. RothSTEIN, "Expanding the Ethical Analysis of Biobanks", The Journal of Law, Medicine \& Ethics, $\mathrm{n}^{\circ} 1$ (2005), pp. 95 y s.; Don Chalmers, "Ethical Principles for Research Governance of Biobanks", Journal of International Biotechnology Law, $\mathrm{n}^{\circ} 3$ (2006), p. 228. 
tante, que debe estar prevista en el proyecto de investigación y a la que el Comité de Ética de la Investigación debe prestar una especial atención $^{53}$. Cuando un participante desee recibir los resultados del análisis ("feedback"), deberá ser requerido para que informe de la manera de ponerse en contacto él, así como que mantenga a los investigadores informados sobre sus cambios de residencia. En tal caso, también habrá de ser advertido de la implicación de la información que se pudiera obtener para sus familiares y la conveniencia de que él mismo, en su caso, transmita dicha información a aquellos;

En cualquier caso, el contenido de la información prevista en el mencionado art. 59 LIB, no puede entenderse como numerus clausus. Así, además de los anteriores, debe informarse también al sujeto fuente de las siguientes cuestiones: a) del carácter gratuito de la cesión (sin perjuicio de una posible compensación que pueda estimarse adecuada $)^{54}$; b) de la inexistencia de derechos económicos para el mismo en el caso de que éstos se produzcan como resultado de la investigación (por ejemplo, derivados de una patente o de la comercialización del producto resultante $)^{55}$; c) de la fuente de financiación del proyecto de investigación ${ }^{56}$; d) de que él o su familia podrán hacer uso de las

${ }^{53}$ Por ejemplo, deben preverse cuestiones tales como la persona que debe ponerse en contacto con el donante (el investigador principal, su médico, etc.), o el hecho que los resultados de un análisis pueden no resultar del todo fiables, puesto que los estándares de calidad empleados en la investigación biomédica pueden ser distintos de aquéllos utilizados para el diagnóstico clínico. Por ello, debería requerirse la comprobación del resultado por un segundo laboratorio antes de contactar con el donante.

Vid. Medical Research Council, Human Tissue and biological samples for use in research. Operational and ethical guidelines, 2001, pp. 18 y ss.; GERMAN NATIONAL ETHICS CouncIL, Biobanks for Research, 2004, pp. 59 y s.

${ }^{54}$ Cfr. arts. 7.I y 58.3 LIB. Vid. Amelia Martín URANGa/M ${ }^{a}$ Concepción MARTín-ARrIBAS/Jeanne-Hélène DI DonATO/Manuel PosADA DE LA PAZ, Las cuestiones ético-jurídicas más relevantes en relación con los biobancos, Instituto de Salud Carlos III-Ministerio de Sanidad y Consumo, Madrid, 2005, pp. 55 y ss.; M. DeschêNES/G. CARDINAL/B.M. KNOPERS/K.C. GLASS, "Human genetic research, DNA banking and consent: a question of 'form'?", Clinical Genetics, $\mathrm{n}^{\circ} 59$ (2001), p. 230.

${ }^{55} \mathrm{Cfr}$. art. 7.II LIB. En el mismo sentido, Medical Research Council, Human Tissue and biological samples for use in research. Operational and ethical guidelines, 2001, p. 12; Carlos María Romeo Casabona, "Utilización de muestras biológicas y bancos para la investigación biomédica", IV Congreso Mundial de Bioética. Ponencias y comunicaciones, Sociedad Internacional de Bioética, Gijón, 2005, p. 89; GRUPO PARA el Uso DE Muestras BiolóGiCAS PARA INVESTIGACIÓN BIOMÉDICA, Guía práctica para la utilización de muestras biológicas en investigación biomédica, Instituto Roche, Madrid, 2006, p. 98; COMITÉ DE ÉTICA DEL INSTITUTO DE INVESTIGACIÓN DE ENFERMEDADES RARAS, "Recomendaciones sobre los aspectos éticos de las colecciones de muestras y bancos de materiales humanos con fines de investigación biomédica”, Revista Española de Salud Pública, nº 2 (2007), pp. 104 y 108 y s.

${ }^{56}$ Cfr. art. 15.2.i) LIB. Vid. también, M. Deschênes/G. CARDinaL/B.M. KNOPERS/K.C. GLASS, "Human genetic research, DNA banking and consent: a question of 'form'?", Clinical Genetics, n 59 (2001), p. 229. 
muestras en caso necesario por razones de salud (art. 58.4 LIB); e) en el caso de que la muestra sea conservada, de las condiciones de conservación, objetivos, usos futuros, cesión a terceros y condiciones para poder retirarlas o pedir su destrucción (art. 61.1 LIB).

Cuando se trate de muestras biológicas que vayan a ser sometidas a un proceso de anonimización ${ }^{57}$, el apartado segundo de este mismo art. 59 prevé que el sujeto fuente recibirá, en tal caso, únicamente la información contenida en la letras a), b), c) y d) anteriormente referidas. Además, el sujeto fuente deberá ser informado de que no será posible revocar dicho consentimiento puesto que ya no va a ser posible relación la muestra con su identidad ${ }^{58}$.

Por otro lado, el valor de la muestra puede incrementarse permitiendo a otros investigadores tener acceso a la misma. La LIB prevé esta posibilidad cuando establece que "el consentimiento específico podrá prever el empleo de la muestra para otras líneas de investigación relacionadas con la inicialmente propuesta, incluidas las realizadas por terceros. Si no fuera éste el caso, se solicitará al sujeto fuente que otorgue, si lo estima procedente, un nuevo consentimiento" (art. 60.2 LIB) ${ }^{59}$. Nos encontramos, pues, ante la posibilidad de otorgar un consentimiento que podemos denominar específico amplio $^{60}$. Por supuesto, tales cesiones a terceros deben ser excepcionales y deben quedar plenamente documentadas, de tal forma que el sujeto fuente

${ }^{57}$ De hecho, la utilización de muestras anonimizadas debería ser la regla general, y utilizar muestras relativas a un sujeto identificado o identificable únicamente cuando ello sea imprescindible dada la naturaleza de la investigación que desea llevarse cabo. Así lo recoge claramente la Recomendación del Consejo de Europa $\mathrm{n}^{\circ} 4$ (2006), on biological materials of human origin. Por ejemplo, en su art. 8 establece que las muestras biológicas y sus datos asociados deberían ser anonimizados en la medida en ello sea apropiado para la investigación en cuestión. Y a continuación añade que cualquier uso de muestras biológicas identificadas o identificables debería esta justificado por el investigador.

${ }^{58}$ Lo cierto es que, tal y como señala Henry T. GreELY, "The Uneasy Ethical and Legal Underpinning of Large-Scale Genomic Biobanks", Annual Review of Genomics and Human Genetics, $\mathrm{n}^{\circ} 8$ (2007), p. 352, en algunos casos, especialmente cuando se trate de incluir las muestras biológicas y la información asociada a las mismas en grandes biobancos poblacionales, es posible que la anomización de las muestras no sea ya una opción disponible, debido a la posibilidad de llegar a conocer la identidad del sujeto fuente por medio de la información sobre su persona que consta en la base de datos. En tales casos, dice este autor, los formularios de consentimiento deben ser honestos y decir algo del siguiente tenor: «haremos lo máximo posible por mantener su identidad en secreto, pero no podemos garantizarlo totalmente. $\mathrm{Si}$ alguien realmente quisiera conocer la identidad de un sujeto en esta base de datos, podría hacerlo».

${ }^{59}$ Cfr. M. DeschêNES/G. CARDINAL/B.M. KNOPERS/K.C. Glass, "Human genetic research, DNA banking and consent: a question of 'form'?", Clinical Genetics, n' 59 (2001), p. 225.

${ }^{60}$ Frente a un consentimiento específico restringido, que limitaría la utilización de la muestra biológica única y exclusivamente a aquellas investigaciones concretas para las cuales éste ha sido prestado. 
pueda seguir en todo momento el rastro de su muestra y la información obtenida de la misma ${ }^{61}$.

La información deberá transmitirse a la persona que vaya a prestar el consentimiento. Como dijimos más arriba, corresponde al investigador valorar la capacidad real del participante en la investigación. Para ello serán de aplicación las reglas generales contenidas en la Ley $41 / 2002^{62}$, en concordancia con lo dispuesto en la LIB. De esta forma, la capacidad se presumirá en sujetos mayores de dieciséis años no incapacitados, si bien es posible que en ciertas circunstancias un sujeto mayor de esa edad no incapacitado no sea capaz de prestar un consentimiento válido (por ejemplo, porque está inconsciente o porque sufre un trastorno mental incapacitante).

Desde un punto de vista teórico, podría plantearse la posibilidad de que un determinado sujeto fuera capaz para consentir la obtención de la muestra, pero no para decidir sobre su destino. Por ejemplo, su capacidad de entendimiento le permite comprender los efectos de la intervención corporal dirigida a obtención del material biológico, pero no las explicaciones sobre el proyecto de investigación, y sus consecuencias para su persona. Ante esta situación, habría que preguntarse si el consentimiento para la extracción de la muestra debería prestarlo el sujeto fuente, mientras que la prestación del consentimiento para su uso correspondería el representante legal. Esta conclusión no parece admisible, pues resulta muy poco funcional en la práctica y claramente distorsionadora. Lo más correcto en estos casos será solicitar el consentimiento del representante legal del sujeto fuente, tanto en relación con la obtención como respecto al destino posterior de la muestra biológica, sin perjuicio de que éste sea también informado y se le haga partícipe del proceso deliberativo y de toma de la decisión. Esta solución parece la más adecuada, especialmente si tenemos en cuenta, tal y como expusimos más arriba, que la capacidad para consentir la extracción de la muestra está estrechamente ligada al uso posterior de la misma.

Cuando el menor de edad que fue considerado incapaz adquiera una suficiente capacidad de juicio, podrá manifestar su voluntad sobre dicha muestra (si aún está siendo utilizada). Igualmente, tratándose de personas adultas incapacitadas (p. ej., aquellos que sufren una enfermedad mental), hay que tener en cuenta que la falta de capacidad puede ser temporal o recurrente (con

\footnotetext{
${ }^{61}$ En ocasiones, el investigador subcontrata un determinado análisis de la muestra a un laboratorio externo. Esta entrega de la muestra no se considera cesión a terceros a los efectos de la LIB. Cfr. Grupo PARA El Uso de Muestras Biológicas PARA InVESTIGACión BioméDICA, Guía práctica para la utilización de muestras biológicas en investigación biomédica, Instituto Roche, Madrid, 2006, p. 139.

${ }^{62} \mathrm{Vid}$. al respecto, Carlos M. Romeo CASABona/Aitziber Emaldi Cirión/ Leire Escajedo San Epifanio/Pilar Nicolás Jiménez/Sergio Romeo Malanda/Asier UrRuela Mora, La Ética y el Derecho ante la biomedicina del futuro, Universidad de Deusto, Bilbao, 2006, pp. 27 y ss.
} 
periodos de lucidez), y el grado de capacidad del sujeto puede variar, de tal modo que pueda esperarse a que el sujeto recobre la capacidad, siquiera temporal. Si no es así, una vez éste se encuentre en un periodo de lucidez habrá de ser informado y deberá consentir por sí mismo la participación en dicha investigación o su eventual rechazo. También deberá respetarse la voluntad emitida por el sujeto durante momentos anteriores a la incapacidad sobre deseos acerca de la participación en la investigación.

\subsubsection{Muestras biológicas recogidas con una finalidad distinta a la investigación} que también desean emplearse con fines de investigación

Cuando las muestras biológicas se obtienen con una finalidad distinta a la investigación (por ejemplo, para un diagnóstico o en el curso de una intervención médica $)^{63}$, es posible que éstas puedan resultar de interés para la ciencia y que se requiera su cesión para ser empleadas en un proyecto de investigación, o para ser almacenadas en un biobanco con esta misma finalidad. En tales casos, puede suceder que este deseo de destinar la muestra biológica a un fin secundario de investigación sea conocido ya en el momento de la obtención, o que sobrevenga al mismo.

A este respecto, el art. 58.2 LIB establece que "el consentimiento del sujeto fuente será siempre necesario cuando se pretendan utilizar con fines de investigación biomédica muestras biológicas que hayan sido obtenidas con una finalidad distinta, se proceda o no a su anonimización" ${ }^{64}$. Por su parte, el art. 60.1 LIB dispone que "el consentimiento se otorgará, bien en el acto de obtención de la muestra, bien con posterioridad, de forma específica para una investigación concreta". Ello dependerá de que la la finalidad secundaria de investigación se conozca ya en el momento de la obtención o no.

\subsubsection{LA FINALIDAD SECUNDARIA DE INVESTIGACIÓN ES CONOCIDA EN EL MO- MENTO DE LA OBTENCIÓN}

Cuando en el momento de la obtención de la muestra biológica se ha previsto ya su uso con fines secundarios de investigación, en ese mismo instante se pedirá al sujeto fuente su consentimiento para dicho fin, en los mismos términos y con similares requisitos que los vistos más arriba al referirnos a la uti-

\footnotetext{
${ }^{63}$ V. Sergio Romeo MaLANDA, "La utilización de materiales biológicos humanos con fines diagnósticos y terapéuticos", Estudios de Deusto, Vol. 56, n 1 (2008), pp. 161-213.

${ }^{64}$ En este mismo sentido se pronuncian la Ley 7/2002, de 10 de diciembre, de Ordenación Sanitaria de Cantabria, cuyo art. 39.3 establece que "el paciente tendrá derecho a estar informado sobre la conservación de tejidos y muestras biológicas provenientes de una biopsia, extracción o donación debiendo obtenerse autorización para usos diferentes a su propio tratamiento"; así como la Ley riojana 2/2002, de 17 de abril, de Salud: "El paciente tendrá derecho a estar informado sobre la conservación de tejidos o muestras biológicas provenientes de una biopsia, extracción o donación debiendo obtenerse autorización para su uso" [art. 9.2.a)].
} 
lización de la muestra biológica obtenida con fines directos de investigación. No obstante, cabe hacer aquí alguna consideración adicional.

Cuando el sujeto fuente está incurso en un procedimiento médico, en el que se han obtenido muestras biológicas (con fines diagnósticos o terapéuticos), las cuales desean emplearse también para investigación, hay que tener en cuenta que el nivel de estrés de estos sujetos puede ser mayor al normal en tales circunstancias y por ello, puede ser más dificil tomar decisiones complejas relativas a cuestiones que no tienen que ver directamente con su atención médica ${ }^{65}$. Puesto que el presupuesto básico para un consentimiento válido es la capacidad del paciente de entender lo que se le está proponiendo, es obligatorio que los investigadores distingan claramente entre tratamiento médico e investigación biomédica. Es decir, al paciente hay que dejarle claro que permitir la investigación con su muestra biológica no tiene nada que ver con un uso clínico de la misma.

Además, debe valorarse también el posible riesgo de coerción cuando el médico que está tratando al paciente es a la vez investigador y pretende que su paciente ceda la muestra biológica para un proyecto en el que él participa. Hay una diferencia importante entre el caso del sujeto que decide ceder sus muestras para la investigación al margen de una relación médico-paciente y el de la persona que está bajo la atención médica de un facultativo que le pide la cesión de sus muestras. En este contexto, algún paciente podría ver peligrar la atención sanitaria si no consiente el uso de las muestras biológicas en investigación. Por ello, es recomendable que en estos casos el consentimiento para la obtención de la muestra y su uso diagnóstico, y el consentimiento para su posible destino a la investigación se recaben en dos procesos diferentes y en documentos distintos ${ }^{66}$. Una forma de consentimiento separada supone, efectivamente, un mayor tiempo para el hospital o centro sanitario y para su personal. Sin embargo, es esencial ase-

${ }^{65}$ Cfr. Garrath Williams/Doris Schroeder, "Human Genetic banking: altruism, benefit and consent", New Genetics and Society, n 1 (2004), p. 92; W. LIPWORTH/R. ANKENY/I. KeRRIDGE, "Consent in crisis: the need to reconceptualize consent to tissue banking research", Internal Medicine Journal, no 36 (2006), p. 126; Michael BARR, "'I'm not Really read up on Genetics': Biobanks and the Social Context of Informed Consent", BioSocieties, $\mathrm{n}^{\circ} 1$ (2006), p. 256. Por esta razón, en ciertos casos podría no resultar apropiado pedir el consentimiento en tales circunstancias. Por otro lado, algunos centros de investigación han optado por aplicar un procedimiento de obtención del consentimiento en dos etapas ("two stage consent process"). Así, se obtiene un primer consentimiento en el momento de obtención de la muestra referente a su uso secundario con fines de investigación. Pero para asegurarse de que dicho consentimiento ha sido realmente válido, transcurrido un cierto tiempo se vuelve a contactar con el sujeto fuente (o su representante legal) para informarle del uso que se está dando a la muestra, de tal forma que éste tiene una nueva oportunidad para manifestar su voluntad al respecto. Vid. Australian Law Reform Commission, Essentially Yours: The Protection of Human Genetic Information in Australia, Vol. I, 2003, pp. 483 y 517.

${ }^{66} \mathrm{Cfr}$. Medical Research Council, Human Tissue and biological samples for use in research. Operational and ethical guidelines, 2001, p. 10; IRISH COUNCIL FOR BIOETHICS, Recommendations on the collection, use and storage of human biological material in research (2005), Recomendación 3. 
gurarse de la validez del consentimiento y la capacidad y libertad del sujeto en el momento de prestarlos, así como garantizar los derechos del mismo.

Además, en el momento de prestar el consentimiento, el sujeto fuente debe tener muy claro que su negativa no afectara en modo alguno a la calidad del tratamiento médico que está recibiendo. A este respecto, el art. 6 LIB señala que no " $(. .$.$) podrá discriminarse a una persona a causa de su negativa$ (...) a donar materiales biológicos, en particular en relación con la prestación médico-asistencial que le corresponda". Del mismo modo, es importante informar a los pacientes del destino del material biológico excedente si no dan su consentimiento para su uso con fines de investigación ${ }^{67}$.

Por otro lado, la utilización de parte del material biológico con fines de investigación biomédica «no puede interferir ni con el diagnóstico histopatológico, citomorfológico, fenotípico o molecular del caso, ni con el uso para otro tipo de fines primordiales para el paciente, como la evaluación de los parámetros pronósticos; en otras palabras, sólo se podrá utilizar para el archivo el material excedente del utilizado para los fines anteriormente citados» ${ }^{68}$.

Por último, y en cierta manera vinculado a lo anterior, resulta necesario señalar que en este tipo de actuaciones deberá respetarse el principio de necesidad y suficiencia de la muestra. Es decir, el profesional sanitario que tome la muestra biológica tiene el deber de obtener únicamente la cantidad estrictamente necesaria para el fin principal propuesto. No debe haber una intención de obtener material excesivo, mayor al requerido para el fin principal (diagnóstico o terapéutico), para poder plantear posteriormente al sujeto fuente su cesión con otros fines. Si el profesional desea un uso ulterior, y para ello requiere más muestras de las necesarias para el fin principal, deberá informar de ello al paciente para que este pueda dar su consentimiento. Cuando el sujeto fuente autoriza la toma de una muestra, debe entenderse que autoriza la obtención del material biológico absolutamente imprescindible para el fin requerido $^{69}$. Lo ideal es que se informe previamente al sujeto la cantidad de ma-

\footnotetext{
${ }^{67}$ Medical Research Council, Human Tissue and biological samples for use in research. Operational and ethical guidelines, 2001,p. 10. Según el art. 9.2.b) de la Ley riojana 2/2002, de 17 de abril, de Salud, "cuando el paciente no autorice el uso de tejidos o muestras biológicas provenientes de una biopsia o extracción se debe proceder a su eliminación como residuo sanitario, eliminación que se efectuará de acuerdo a la normativa vigente".

${ }^{68}$ Grupo PaRA El Uso de Muestras BiológicAs PARA Investigación Biomédica, Guía práctica para la utilización de muestras biológicas en investigación biomédica, Instituto Roche, Madrid, 2006, p. 25.

${ }^{69}$ NufField Council On Bioethics. Human tissue. Ethical and Legal issues (London, 1995), p. 24. Cuando se requiera tomar muestras adicionales, corresponderá al Comité de Ética de la Investigación correspondiente valorar los riesgos que supone la obtención de tales muestras, así como su justificación. Igualmente, debe asegurar que la información que recibe el paciente incluye la explicación de dicha toma adicional de muestras. Cfr. GRUPO PARA EL UsO DE MuESTRAS BIOLÓGICAS PARA INVESTIGACIÓN BIOMÉDICA, Guía práctica para la utilización de muestras biológicas en investigación biomédica, Instituto Roche, Madrid, 2006, p. 40.
} 
terial biológico que se van a obtener y que se justifique la misma, sin perjuicio de que, por motivos terapéuticos, pueda ser necesario extraer más material del previamente previsto. Pero tal eventualidad debería ser también adelantada al paciente. Además, hay que garantizar que el tratamiento medico es realmente necesario, y la obtención de la muestra es parte del mismo. El tratamiento no puede ser un pretexto para obtener tejidos que puedan ser utilizados con otros propósitos ${ }^{70}$. En estos casos, la falsedad de la información transmitida invalidará el consentimiento prestado.

\subsubsection{LA FINALIDAD SECUNDARIA DE INVESTIGACIÓN ES SOBREVENIDA}

Tal y como dijimos más arriba, "el consentimiento del sujeto fuente será siempre necesario cuando se pretendan utilizar con fines de investigación biomédica muestras biológicas que hayan sido obtenidas con una finalidad distinta (...)" (art. 58.2 LIB). Cuando dicho destino secundario de la muestra no se conozca aún el acto de obtención, entonces el consentimiento relativo a la utilización de la muestra biológica se otorgará con posterioridad (cuando se plantee el nuevo uso), de forma específica para una investigación concreta (art. 60.1 LIB). En definitiva, si el material relativo a una persona identificada o identificable permite conocer y contactar con el sujeto fuente, entonces sobre el investigador recae la responsabilidad de ponerse en contacto con dicho sujeto (o sus familiares, de acuerdo con las reglas más arriba expuestas), para obtener el consentimiento del mismo a fin de utilizar las muestras biológicas existentes para el nuevo fin pretendido.

No obstante, como veremos más abajo, pueden presentarse algunos inconvenientes a la hora de intentar recontactar con estas personas ${ }^{71}$. Posteriormente analizaremos la cuestión de si en ciertas circunstancias y con ciertos requisitos puede ser admisible la utilización de muestras biológicas de una persona sin contar con su consentimiento. En principio, a fin de evitar tales inconvenientes, la solución pasaría por solicitar siempre a los pacientes que den su consentimiento en el momento de obtener una muestra biológica para que ésta pueda ser empleada con fines de investigación biomédica en un futuro aún indeterminado. En este caso el consentimiento debería ser muy amplio y genérico, ya que aún se desconoce la investigación o investigaciones concretas a las que va a ser des-

\footnotetext{
${ }^{70}$ Nuffield Council on Bioethics. Human tissue. Ethical and Legal issues (London, 1995), pp. 46 y s.

${ }^{71}$ En ciertas circunstancias puede resultar extremadamente dificultoso o, incluso, imposible para los investigadores recontactar con los individuos y obtener el debido consentimiento para la utilización de las muestras biológicas. El material puede haber sido almacenado durante largos periodos de tiempo, el sujeto fuente puede haber fallecido o resultar ilocalizable. Y en muchos casos, puede ser prohibitivamente costoso recontactar con un gran número de personas para solicitar su consentimiento (especialmente en estudios de carácter académico).
} 
tinado $^{72}$. Por esta razón, ello únicamente será posible si la muestra va a ser incorporada a un biobanco, en los términos establecidos en el art. 69 LIB.

De lege ferenda también sería posible recoger una presunción legal, de tal forma que todas las muestras biológicas obtenidos con fines diagnósticos y terapéuticos que ya no vayan a ser destinadas a dicha finalidad, podrían ser utilizadas con fines de investigación biomédica siempre que el sujeto fuente no haya manifestado su voluntad contraria a ello ${ }^{73}$. Así lo prevé, por ejemplo, la

${ }^{72}$ Para Francesc Abel/Victoria Cusí, "Bancos de información genética. Problemas éticos y jurídicos" en Xavier Abel Lluch (dir.), El juez civil ante la investigación biomédica, Cuadernos de Derecho Judicial, Vol. X, Consejo General del Poder Judicial, Madrid, 2004, p. 458, "es recomendable solicitar un consentimiento general para poder utilizar un posible excedente de tejido para la investigación y docencia; o al revés, la negativa a dar este consentimiento. En ambos casos se debe dejar constancia por escrito". Y en otro lugar afirma: "Es conveniente que los documentos de CI que se utilicen para intervenciones quirúrgicas, incluyan un apartado donde se contemple la aprobación del paciente para que el tejido sobrante, después de ser utilizado para el diagnóstico histopatológico correcto, pueda ser utilizado con fines de investigación o de docencia" (pp. 460 y s.).

${ }^{73}$ Vid. sobre este particular, Peter FURNESS, "Consent to using human tissue: implied consent should suffice", British Medical Journal, n 327 (2003), pp. 759 y s. A este respecto, según apunta Sven Ove Hansson, "The ethics of biobanks", Cambridge Quarterly of Healthcare Ethics, $\mathrm{n}^{\circ} 13$ (2004), pp. 321 y s., en Dinamarca, un comité oficial ha propuesto la creación de un registro especial donde quede constancia de la negativa de un sujeto a ceder muestras biológicas con fines de investigación. De esta forma, los biobancos tendrían que comprobar en dicho registro si una determinada persona cuyo material biológico podría ser destinado a la investigación ha manifestado su voluntad contraria al respecto. En caso contrario, dicho material (por ejemplo, tejido procedentes de una intervención quirúrgica) podría ser empleado sin requerir el consentimiento expreso del sujeto fuente.

Un buen ejemplo de consentimiento presunto en el ámbito de la investigación biomédica es el caso islandés. Este caso resultó especialmente controvertido puesto que la gestión centralizada de todas las historias clínicas de los islandeses (Ley 139/1998, sobre bases de datos de salud), y posteriormente de su material biológico (Ley 119/2000, sobre biobancos), sería gestionada por una empresa privada (deCODE Genetics). Los art. 8 Ley 139/1998 y 7 Ley $117 / 2000$ establecen la regla del consentimiento presunto. Este modelo, sin embargo, ha suscitado muchas críticas y una sentencia en contra del Tribunal Supremo de Islandia (de 27 de noviembre de 2003) [el texto de la sentencia puede consultarse en la Revista de Derecho y Genoma Humano, $\mathrm{n}^{\circ} 21$ (2004), pp. 127 y ss.], por lo que ha sido de facto abandonado. Vid. al respecto, Hróbjartur JónATANSSON, "Iceland's Health Sector Database: A significant head Stara in the Search for the Biological Grail or an Irreversible Error?", American Journal of Law and Medicine, $\mathrm{n}^{\circ} 26$ (2000), pp. 31 y ss.; Skúli SigurdSSON, "Yin-yang genetics, or the HSD deCODE controversy", New Genetics and Society, n 2 (2001), pp. 1003 y ss.; Ragnar AdALSTEInSSON, "The constitutionality of the Icelandic Act on a Health Sector Database", en Judit Sandor (Ed.), Society and Genetic Information: Codes and Laws in the Genetic Era, Central European University Press, Budapest, 2003,pp. 203 y ss.; Renate GERTZ “An analysis of the Icelandic Supreme Court judgement on the Health Sector Database Act", SCRIP$e d$ (on line journal), $\mathrm{n}^{\circ} 2$ (2004), pássim; Roberto ANDORNO, "Biobancos poblacionales: un análisis jurídico a partir de las experiencias islandesa y estonia", Revista de Derecho y Genoma Humano, no 25 (2006), pp. 57 y ss.; Yael BREGMAN-Eschet, "Genetic Databases and Biobanks: Who controls our Genetic Privacy?", Santa Clara Computer and High - Technology Journal, $\mathrm{n}^{\circ} 23$ (2006), pp. 37 y ss. 
Ley 8/2003, de 8 de abril, de la Comunidad Autónoma de Castilla y León, sobre derechos y deberes de las personas en relación con la salud. Según su art. 36.2, "en el marco de la normativa aplicable, y siempre que no exista oposición por parte del interesado, los centros, servicios y establecimientos sometidos a la presente Ley podrán conservar y utilizar tejidos o muestras biológicas para fines lícitos distintos de aquéllos que motivaron la biopsia o extracción"74.

\subsubsection{Revocación del consentimiento para el uso de la muestra biológica. Efectos sobre la muestra}

Un elemento inseparable del requisito de consentimiento es la facultad del sujeto de la revocación del mismo ${ }^{75}$. Esta facultad de revocación del con-

${ }^{74}$ La Disposición final primera de la LIB establece que "esta Ley se aprueba al amparo del artículo 149.1.15. ${ }^{a}$ y 16. ${ }^{a}$ de la Constitución Española, que atribuye al Estado la competencia exclusiva en materia de fomento y coordinación general de la investigación científica y técnica y en materia de bases y coordinación general de la sanidad. El Estado y las comunidades autónomas adoptarán, en el ámbito de sus respectivas competencias, las medidas necesarias para garantizar la efectividad de esta Ley". De esta forma, el legislador estatal se ha irrogado la competencia exclusiva para regular las materias objeto de la presente ley, correspondiendo a las comunidades autónomas, como se ha dicho, únicamente la adopción de las medidas necesarias para garantizar su efectividad.

Por lo tanto, cabe preguntarse cuál es el efecto que la LIB tendrá sobre la mencionada disposición de la ley castellano-leonesa. Para evitar la consideración del referido precepto como inconstitucional (por haber regulado una materia sobre la cual la comunidad autónoma no tenia competencia, lo cual habría que aclarar con carácter previo), la solución más adecuada sería llevar a cabo una interpretación de los preceptos estatales y autonómicos que permita conjugar su aplicación, mostrando que la contradicción entre ellos es meramente aparente, y en su caso haciendo prevalecer la interpretación de las leyes que es conforme con la Constitución y el orden constitucional de competencias (STC 236/2000, de 16 de octubre, fundamentos jurídicos 3 y 5, y art. 5 de la Ley Orgánica 6/1985, de 1 de julio, del Poder Judicial).

Ello es posible en relación con el art. 36.2 de la referida Ley 8/2003 (Comunidad Autónoma de Castilla y León). El propio artículo prevé su aplicación "en el marco de la normativa aplicable", la cual será la LIB en relación con el uso de muestras biológicas con fines de investigación. De esta forma, este precepto no será aplicable en aquellos ámbitos en los que la legislación estatal regula un uso de muestras biológicas con carácter exclusivo, pero sí lo será en aquellos otros en los que la Comunidad Autónoma tenga capacidad legislativa.

${ }^{75}$ Así, por ejemplo, el art. 9 de la Declaración Internacional de la UNESCO sobre los Datos Genéticos Humanos, de 16 de octubre de 2003, establece que "a) Cuando se recolecten (...) muestras biológicas con fines de investigación médica y científica, la persona de que se trate podrá revocar su consentimiento, a menos que esos datos estén irreversiblemente disociados de una persona identificable. (...) [L]a revocación del consentimiento no debería acarrear ningún perjuicio o sanción para la persona interesada; b) Cuando alguien revoque su consentimiento, deberían dejar de utilizarse sus (...) muestras biológicas a menos que estén irreversiblemente disociados de la persona en cuestión (...)". Por su parte, el art. 22.2 de la 
sentimiento previamente emitido se recoge expresamente en la LIB, primero con carácter general, en su art. 4.3, y posteriormente de forma específica en relación con el uso de muestras biológicas en investigación. Así, el art. 60.3 LIB establece que "el consentimiento podrá ser revocado, totalmente o para determinados fines, en cualquier momento. Cuando la revocación se refiera a cualquier uso de la muestra, se procederá a su inmediata destrucción, sin perjuicio de la conservación de los datos resultantes de las investigaciones que se hubiesen realizado con carácter previo".

De lo anterior se desprende que puede existir una revocación total o parcial (permitiendo la utilización de la muestra en otro tipo de investigaciones). Por otra parte, si el sujeto fuente desea recuperar las muestras por razones sanitarias, el art. 58.4 LIB señala que "cuando, por razones de salud, el sujeto fuente o su familia lo necesiten podrán hacer uso de las muestras, siempre que estén disponibles y no se encuentren anonimizadas" ${ }^{\text {"76 }}$. La referencia a las "razones de salud" debe ser entendida en un sentido amplio, incluyéndose cualquier actuación que se realice en el ámbito sanitario ${ }^{77}$.

Recommendation Rec (2006) 4 of the Committee of Ministers to member states on research on biological materials of human origin, señala, en el mismo sentido, que el participante en un proyecto de investigación podrá revocar el consentimiento en cualquier momento, lo cual no podrá generar ningún tipo de discriminación hacia el mismo, en particular respecto a su derecho a la atención sanitaria.

${ }^{76}$ Como dijimos, lo ideal es que esta eventualidad le sea también comunicada al sujeto fuente en el momento de recabar su consentimiento para el uso de la muestra biológica.

${ }^{77}$ La LIB no resulta aplicable, sin embargo, a otras situaciones que ya se han demostrado controvertidas en la práctica, como es el caso de las muestras biológicas obtenidas con fines diagnósticos, cuando el sujeto desea recuperar dicha muestra para realizar un segundo diagnóstico en otro centro. Los tribunales han emitido sentencias contradictorias al respecto. Vid. Sentencias de la Audiencia Provincial de Vizcaya, de 21 de julio de 2000 (Ponente: María de los Reyes Castresana García) y del Tribunal Superior de Justicia de Cantabria, de 16 de mayo de 2001 (Ponente: Maria Josefa Artaza Bilbao), así como un detallado análisis de las mismas por Pilar NiCOLÁs JiMÉNEZ, "Los derechos del paciente sobre su muestra biológica: distintas opiniones jurisprudenciales", Revista de Derecho y Genoma Humano, nº 19 (2003), pp. 207 y ss.

El principal error de ambas resoluciones ha sido, a nuestro juicio, analizar la cuestión desde la perspectiva del acceso a la información sanitaria y no, como debería haberse hecho, desde la existencia de un posible derecho a la propiedad sobre la muestra. Como afirma NiCOLÁs JiMÉNEZ, "Los derechos del paciente sobre su muestra biológica: distintas opiniones jurisprudenciales", Revista de Derecho y Genoma Humano, no 19 (2003), p. 223, de ambas sentencias parece deducirse que los tribunales atribuyen la propiedad de la muestra biológica al centro donde ésta se encuentra almacenada y no al sujeto fuente (este la habría abandonado y el hospital se habría apropiado de ella). Si como debiera haberse hecho, los tribunales hubieran partido de la consideración del sujeto fuente (el ahora reclamante de la muestra) como propietario de la misma, no habría existido ningún problema para haber ordenado su restitución cuando ésta fue requerida.

En cualquier caso, sería conveniente de lege ferenda un pronunciamiento expreso del legislador, de forma similar a lo dispuesto en algunas leyes autonómicas. Por ejemplo, la Ley 
Así pues, si la revocación del consentimiento afecta únicamente a la identificación de las muestras, éstas podrán anonimizarse y seguir siendo empleadas con fines de investigación biomédica. Si por el contrario, la revocación se refiere a cualquier uso de la muestra, éstas deberán ser destruidas.

Por último, resulta de interés plantearse los efectos jurídicos de la revocación del consentimiento respecto al sujeto fuente, y la eventual responsabilidad patrimonial del mismo si de esta decisión se derivara algún perjuicio para el correcto desarrollo del proyecto de investigación en la que estaba siendo empleada, o en el que iba a utilizarse. No podemos ocuparnos ahora de esta interesante cuestión, pues ello excede el objeto de este trabajo. Sin embargo, sí conviene apuntar que ello ha sido ya planteado en relación con el trasplante de órganos, y esta discusión doctrinal puede trasladarse en similares términos al tema que ahora nos ocupa ${ }^{78}$.

de la Comunidad Autónoma de Castilla y León 8/2003, de 8 de abril, sobre derechos y deberes de las personas en relación con la salud, en cuyo art. 36.1 establece lo siguiente: "Las personas a quienes se practique una biopsia o extracción en los centros, servicios o establecimientos sometidos a la presente Ley tienen derecho a disponer de preparaciones de tejidos o muestras biológicas provenientes de aquéllas, con el fin de recabar la opinión de un segundo profesional o para garantizar la continuidad de la asistencia en un centro, servicio o establecimiento diferente". De la misma manera, el según el art. 39.2 de Ley de Cantabria 7/2002, de 10 de diciembre, de Ordenación Sanitaria de Cantabria (ley posterior a la sentencia mencionada), "el paciente tiene derecho a disponer de aquellas preparaciones de tejidos o muestras biológicas que provengan de una biopsia o extracción, con la finalidad de recabar la opinión de un segundo profesional o para la continuidad de la asistencia en un centro diferente". Y de forma muy similar, la Ley riojana 2/2002, de 17 de abril, de Salud: "El paciente tiene el derecho a disponer de aquellas preparaciones de tejidos o muestras biológicas que provengan de una biopsia o extracción, con la finalidad de recabar la opinión de un segundo profesional o para la continuidad de la asistencia en un centro diferente".

${ }^{78} \mathrm{Vid}$. Victor Angoitia Gorostiaga, "El régimen reglamentario de la extracción y trasplante de órganos", en Carlos María Romeo Casabona (coord.), El nuevo régimen jurídico de los trasplantes de órganos y tejidos, Comares, Granada, 2005, pp. 190 y ss. De hecho, algunos autores, como Ruth CHADWICK/Kåre BERG, "Solidarity and equity: new ethical framework for genetic databases", Nature Reviews Genetics, n 2 (2001), p. 320, consideran que puede ser conveniente replantearse el derecho de los sujetos fuente a revocar su consentimiento una vez que éste ha sido otorgado, esgrimiendo la existencia de deberes de solidaridad para contribuir a la investigación biomédica.

Por el contrario, El Comité DE ÉTICA DEL INSTITUTO DE INVESTIGACIÓN DE ENFERMEDADES RARAS, "Recomendaciones sobre los aspectos éticos de las colecciones de muestras y bancos de materiales humanos con fines de investigación biomédica", Revista Española de Salud Pública, $\mathrm{n}^{\circ} 2$ (2007), p. 104, recoge en su recomendación 12 que la revocación del consentimiento no puede generar ninguna penalización para dicho sujeto. Para Garrath Williams/Doris Schroeder, "Human Genetic banking: altruism, benefit and consent", New Genetics and Society, $\mathrm{n}^{\circ} 1$ (2004), p. 97, mantener intacto el derecho de revocación es importante para mantener la confianza de los participantes en la investigación. Si se elimina o restringe este derecho, muchas personas podrían negarse a ceder sus muestras biológicas para investigación biomédica. 


\subsection{El uso de muestras biológicas para fines diferentes a los autorizados por el sujeto fuente}

Si bien la regla general es la utilización del material biológico únicamente cuando el sujeto fuente haya prestado su consentimiento, puede ocurrir que ello no sea posible en muchos casos, tal y como avanzábamos más arriba. Por ejemplo, varios años después de la extracción, algunos sujetos no tendrán ningún problema para discutir y autorizar el uso de su muestra aún almacenada, pero otros podrán sentirse molestos o angustiados con dicho contacto ${ }^{79}$. Otros sujetos pueden ser difíciles de localizar, o incluso ello puede ser imposible (por ejemplo, han fallecido o han cambiado de residencia). Esta búsqueda supone, indudablemente, una importante inversión de tiempo y dinero, lo cual puede afectar negativamente a la investigación ${ }^{80}$.

En estos casos, tratándose de muestras biológicas relativas a personas identificadas o identificables, aunque no se deriven daños directos para su salud, sí que es posible advertir posibles perjuicios indirectos derivados del uso de las muestras (por ejemplo, el acceso de terceros a información altamente sensible $)^{81}$, además de afectarse a su derecho a la autoderminación, entendido este aquí como el derecho a tener un control sobre su material biológico. La pregunta es, pues, si es posible utilizar tales muestras con fines de investigación en ciertos casos a pesar de la falta de consentimiento del sujeto fuente. Las posibles respuestas a este dilema son muy variadas. Así, podría optarse por una prohibición absoluta de utilizar muestras biológicas sin el consentimiento del sujeto fuente, permitir su utilización pero exigiendo la anonimización de las mismas, autorizarlo pero exigiendo la intervención previa de un Comité de Ética de la Investigación que vele por los intereses de los sujetos fuente de las muestras, etc.

Puesto que uno de los principales inconvenientes radica en el acceso a información muy sensible del sujeto fuente de las muestras, se ha planteado la posibilidad del uso anonimizado de las mismas cuando desean destinarse a la investigación. Se afirma que si estas se anonimizan ya no hará falta pedir el consentimiento al sujeto fuente. Pero ello no deja de plantear problemas. Por

\footnotetext{
${ }^{79}$ Cfr. P. N. Furness/M. L. Nicholson, "Obtaining explicit consent for the use of archival tissue samples: practical issues", Journal of Medical Ethics, $\mathrm{n}^{\circ} 30$ (2003), p. 563

${ }^{80} \mathrm{Cfr}$. Nikolajs ZePs/Barry J. LACOPETTA/Lyn SchofiELD/Jillian M. GEORGE/Jack GoldBLATT, "Waiver of individual patient consent in research: when do potencial benefits to the community outweigh private right?", Medical Journal of Australia, nº 2 (2007), pp. 89 y s.

${ }^{81}$ Cfr. M. DeschêNES/G. CARDINAL/B.M. KNOPERs/K.C. Glass, "Human genetic research, DNA banking and consent: a question of 'form'?", Clinical Genetics, $\mathrm{n}^{\circ} 59$ (2001), p. 226; Mark A. RothsteIn, "Expanding the Ethical Analysis of Biobanks", The Journal of Law, Medicine \& Ethics, $\mathrm{n}^{\circ} 1$ (2005), p. 90; Gert Helgesson/Joakim Dillner/Joyce CARLSON/Claus R. BARTRAM/Mats G. HANSSON, "Ethical framework for previously collected biobank samples", Nature Biotechnology, n 9 (2007), p. 973.
} 
un lado, ciertas investigaciones requieren el uso de muestras identificadas, de tal forma que dado el caso, el sujeto fuente pueda ser contactado para pedir información adicional o, al menos, pueda obtenerse información médica complementaria; por otra parte, esta posibilidad está expresamente vetada por la $\mathrm{LIB}^{82}$. Así, también para la anonimización de las muestras (o de los datos) y su posterior uso se requiere el consentimiento del sujeto fuente. Recordemos que el art. 58.2.I LIB establece que "el consentimiento del sujeto fuente será siempre necesario cuando se pretendan utilizar con fines de investigación biomédica muestras biológicas que hayan sido obtenidas con una finalidad distinta, se proceda o no a su anonimización" (énfasis añadido).

Ahora bien, lo cierto es que existe una aceptación bastante generalizada de que, de forma excepcional y siempre que se respeten ciertas garantías, debería admitirse la posibilidad de utilizar muestras biológicas sin exigirse el consentimiento del sujeto fuente en determinadas circunstancias. Así, por ejemplo, el Comité de Bioética de Cataluña, en su informe titulado Problemas éticos en el almacenamiento y la utilización de muestras biológicas, dice lo siguiente: "Cuando la situación que se plantea es la utilización de muestras obtenidas con anterioridad y no se dispone del consentimiento del paciente, se recomienda el recurso al comité de ética, que deberá valorar los inconvenientes y beneficios individuales y confrontarlos a las pérdidas y beneficios que la investigación podría representar para la sociedad. Hay que recordar que la solicitud de CI [consentimiento informado], cuando fuera posible obtenerlo, podría ocasionar problemas a los participantes por el hecho de revisar su participación en estudios anteriores o de revivir situaciones vividas que no quieren recordar. También se incrementarían notablemente los costes y los márgenes de error como consecuencia de la pérdida de muchas personas de las que no se obtendría el CI"83.

También la Recomendación del Consejo de Europa ${ }^{\circ} 4$ (2006), on research on biological materials of human origin, acepta esta posibilidad como último recurso. Así, en su art. 22.1.ii establece que "si no fuera posible contactar con la persona afectada empleando un esfuerzo razonable, estos materiales biológicos únicamente deberían ser utilizados en un proyecto de investiga-

\footnotetext{
${ }^{82}$ Con la excepción de las muestras biológicas obtenidas con anterioridad a la entrada en vigor de la LIB, tal y como señalaremos posteriormente.

${ }^{83}$ Comité de Bioética de CATAluña, Problemas éticos en el almacenamiento y la utilización de muestras biológicas, Barcelona, 2004, p. 77. Vid. también, IRISH COUNCIL FOR BioETHics, Recommendations on the collection, use and storage of human biological material in research (2005), Recomendación 11; AUSTRALIAN LAW REFORM COMMISSION, Essentially Yours: The Protection of Human Genetic Information in Australia, Vol. I, 2003, pp. 410 y ss.; Francesc ABEL/Victoria Cusí, "Bancos de información genética. Problemas éticos y jurídicos" en Xavier Abel Lluch (dir.), El juez civil ante la investigación biomédica, Cuadernos de Derecho Judicial, Vol. X, Consejo General del Poder Judicial, Madrid, 2004, p. 459.
} 
ción si éste ha sido sometido a una evaluación independiente y se cumplen los siguiente requisitos: a) se trata de una investigación de alto interés científico; b) los fines de la investigación no podrían ser alcanzados utilizando material biológico para el cual se hubiera obtenido el consentimiento oportuno; c) no existe evidencia de que el sujeto afectado se haya opuesto de forma expresa a su uso para investigación”.

El legislador español ha admitido esta posibilidad en la LIB, distinguiendo entre las muestras biológicas obtenidas con anterioridad a la entrada en vigor de la Ley (5 de julio de 2007), y aquellas otras obtenidas con posterioridad a dicho momento.

De este modo, por un lado tenemos la Disposición Transitoria Segunda de la LIB, que se ocupa de las muestras almacenadas con anterioridad a la entrada en vigor de la Ley. De acuerdo con esta disposición, "las muestras biológicas obtenidas con anterioridad a la entrada en vigor de esta Ley podrán ser tratadas con fines de investigación biomédica cuando el sujeto fuente haya dado su consentimiento o cuando las muestras hayan sido previamente anonimizadas. No obstante, podrán tratarse muestras codificadas o identificadas con fines de investigación biomédica sin el consentimiento del sujeto fuente, cuando la obtención de dicho consentimiento represente un esfuerzo no razonable en el sentido que se indica en el párrafo i) del artículo 3 de esta Ley, o no sea posible porque el sujeto fuente hubiera fallecido o fuera ilocalizable. En estos casos se exigirá el dictamen favorable del Comité de Ética de la Investigación correspondiente, el cual deberá tener en cuenta, como mínimo, los siguientes requisitos: a) Que se trate de una investigación de interés general; b) Que la investigación sea menos efectiva o no sea posible sin los datos identificativos del sujeto fuente; c) Que no conste una objeción expresa del mismo; y d) Que se garantice la confidencialidad de los datos de carácter personal".

De acuerdo con esta disposición, pueden hacerse las siguientes consideraciones en relación con las muestras obtenidas y almacenadas antes del 5 de julio de 2007: a) de ser ello posible, lo más adecuado es pedir el consentimiento del sujeto fuente para utilizar muestras biológicas almacenadas con anterioridad a la entrada en vigor de la Ley; b) es posible utilizar dichas muestras sin el consentimiento del sujeto fuente siempre que se anonimicen previamente; c) de forma excepcional, también es posible utilizar muestras identificadas sin el consentimiento del sujeto fuente, pero en tal caso deberán cumplirse ciertos requisitos, que habrán de ser valorados por el Comité de Ética de la Investigación correspondiente, entre los cuales está la exigencia de justificación del uso identificado de las muestras; d) en el caso de que vayan a utilizarse muestras anonimizadas, ello no exime de la intervención del Comité de Ética de la Investigación, cuyo informe es preceptivo en todo caso de acuerdo con el art. 62 LIB. Pero en este caso, el Comité únicamente deberá comprobar la fecha de recogida de las muestras, y se eximirá de la exigencia del consentimiento del sujeto fuente para todas aquellas obtenidas con anterioridad a la entrada en vigor de la ley; e) las muestras pueden ser usadas por 
cualquier persona o institución, independientemente de quién las obtuvo y dónde se encuentran almacenadas.

Por otra parte, en relación con las muestras biológicas obtenidas con posterioridad a la entrada en vigor de la Ley, el art. 58.2.II LIB establece lo siguiente: "No obstante lo anterior [exigencia del consentimiento del sujeto fuente para utilizar con fines de investigación biomédica muestras biológicas que hayan sido obtenidas con una finalidad distinta], de forma excepcional podrán tratarse muestras codificadas o identificadas con fines de investigación biomédica sin el consentimiento del sujeto fuente, cuando la obtención de dicho consentimiento no sea posible o represente un esfuerzo no razonable en el sentido del artículo 3.i) de esta Ley. En estos casos se exigirá el dictamen favorable del Comité de Ética de la Investigación correspondiente, el cual deberá tener en cuenta, como mínimo, los siguientes requisitos: a) Que se trate de una investigación de interés general; b) Que la investigación se lleve a cabo por la misma institución que solicitó el consentimiento para la obtención de las muestras; c) Que la investigación sea menos efectiva o no sea posible sin los datos identificativos del sujeto fuente; d) Que no conste una objeción expresa del mismo; e) Que se garantice la confidencialidad de los datos de carácter personal".

Aunque este precepto está redactado de forma semejante a aquél que se ocupaba de las muestras obtenidas con anterioridad a la entrada en vigor de la ley, sin embargo, el régimen jurídico de uno y otro supuesto difiere de forma sustancial. Ciertamente, la redacción de este precepto es muy deficiente y puede llevar a error si no se interpreta en sus justos términos. Ello se debe a que el legislador ha utilizado la misma técnica legislativa para regular dos supuestos cuyo punto de partida es diferente. Así, en el supuesto que veíamos más arriba (muestras obtenidas con anterioridad a la entrada en vigor de la ley) se parte del hecho de que las muestras en cuestión podrán ser utilizadas con fines de investigación sin el consentimiento del sujeto fuente siempre que se anonimicen, y las reglas especiales contenidas en la mencionada disposición transitoria segunda se exigen únicamente cuando se quieren utilizar esas muestras de forma identificada y sin consentimiento. Por el contrario, en el supuesto que ahora nos ocupa (muestras obtenidas con posterioridad a la entrada en vigor de la ley), la situación es muy otra, pues la voluntad del legislador es muy clara en el sentido de que el investigador en ningún caso puede hacer uso de tales muestras sin el consentimiento del sujeto fuente mediante la simple anonimización de las mismas (tal y como categóricamente establece el art. 58.2.I LIB) ${ }^{84}$.

${ }^{84}$ Este apartado no se encontraba recogido en el texto original del Proyecto de Ley (Boletín Oficial de las Cortes Generales. Congreso de los Diputados, Serie A, Número 104-1, de 22 de septiembre de 2006), sino que fue introducido en el trámite de enmiendas a petición del Grupo Parlamentario Socialista, con la siguiente motivación: «Según el artículo 58.2 del Proyecto de Ley, no es posible utilizar muestras biológicas simplemente anonimizándolas. Por ello, en cuanto a la utilización de muestras biológicas con fines de investigación biomédica no consentidos por el sujeto fuente, pero sin oposición expresa del mismo, se propone que en 
Así pues, la excepción prevista en el art. 58.2.II LIB debe ser interpretada, a nuestro juicio, de la manera siguiente: a) esta regla será de aplicación siempre que se quiera utilizar muestras biológicas sin el consentimiento del sujeto fuente, tanto si se desea su uso identificado, codificado o completamente anónimo (tras haber sido sometidas al correspondiente proceso de anonimización); b) las muestras se utilizarán preferentemente de forma anonimizada, pero podrán utilizarse de forma identificada y codificada si el investigador justifica que la investigación sería menos efectiva o inviable en caso contrario ${ }^{85} ;$ c) incluso cuando el investigador acepte la utilización de las muestras de forma anonimizada, ello no elimina la obligación de cumplir el resto de los requisitos exigidos en el precepto analizado, esto es, que se acredite fehacientemente por los medios oportunos (que deberá valorar el Comité de Ética de la Investigación correspondiente) que la obtención del consentimiento no es posible o representa un esfuerzo no razonable; que se trata de una investigación de interés general; que la investigación se va a llevar a cabo por la misma institución que solicitó el consentimiento para la obtención de las muestras; que no consta una objeción expresa por parte del sujeto fuente; y que el proceso de anonimización garantiza la confidencialidad de los datos de carácter personal; d) el ámbito de personas que pueden hacer uso de este material biológico está mucho más reducido que en el caso de muestras obtenidas con anterioridad a la entrada en vigor de la ley, pues ahora únicamente la institución que solicitó el consentimiento para la obtención de las muestras puede utilizarlas para este nuevo uso no previsto originariamente ${ }^{86}$. En definitiva, una muestra biológica que haya sido obtenida y almacenada con posterioridad al

algún caso muy excepcional y con todas las garantías se permita utilizar muestras biológicas con fines distintos - de investigación biomédica- a los consentidos originariamente por el sujeto fuente. Ello debido a que en ciertas circunstancias puede resultar extremadamente dificultoso o, incluso, imposible para los investigadores volver a contactar con los interesados y obtener el debido consentimiento para la utilización de las muestras biológicas archivadas» (Boletín Oficial de las Cortes Generales. Congreso de los Diputados, Serie A, Número 10412, de 28 de diciembre de 2006, enmienda n ${ }^{\circ} 167$, p. 136).

${ }^{85}$ En tal caso, deberá elaborarse un protocolo de actuación que establezca claramente el procedimiento a seguir en el caso de que se obtenga información médica de interés para los sujetos cuyas muestras biológicas se están utilizando (si éstos van a ser contactados para recibir la información, cómo se va a llevar a cabo este contacto, quién será el encargado de hacerlo, etc.). El Comité de Ética de la Investigación deberá evaluar y aprobar este protocolo. Vid. Grupo para el Uso de Muestras Biológicas para Investigación Biomédica, Guía práctica para la utilización de muestras biológicas en investigación biomédica, Instituto Roche, Madrid, 2006, pp. 147 y s. (Caso práctico 3).

${ }^{86} \mathrm{El}$ término institución es más amplio que el de centro. De esta forma, aunque la MB se recoja por el servicio de patología u oncología de un determinado hospital (centro), quizás podría ser empleado en un proyecto de investigación del área de dermatología del mismo hospital, o de otro hospital del servicio de salud correspondiente (institución de la que depende el centro, y que es, en ultima instancia, la responsable de lo que suceda). 
5 de julio de 2007 nunca podrá cederse a terceros (ajenos a la institución en cuestión) con fines de investigación sin el consentimiento del sujeto fuente. Por ello, si se considera que dicho material biológico puede resultar de utilidad para futuras investigaciones, es conveniente prever esta posibilidad en el momento de la obtención del mismo y actuar en consecuencia, informando al sujeto fuente y pidiendo el consentimiento del mismo en los términos expresados en la LIB y referidos en el presente trabajo.

En cualquier caso, tanto cuando se trate de muestras biológicas obtenidas con anterioridad a la entrada en vigor de la Ley, como con posterioridad a dicho momento, la regla general debería ser la utilización anonimizada de las mismas ${ }^{87}$. A este respecto, hay que tener en cuenta que ha sido precisamente la imposibilidad de localizar o contactar con el sujeto fuente la que lleva a plantearse la búsqueda de una solución alternativa. En ningún momento hay que perder de vista que el derecho a la investigación científica ${ }^{88}$ que pretende garantizarse con esta previsión legal debe ejercerse siempre con pleno respecto a los derechos de los participantes de la misma, en este caso, los derechos a la intimidad y a la protección de datos ${ }^{89}$, de tal modo que en aquellos casos en los que la Ley prevea una limitación de los mismos ${ }^{90}$, ésta deberá llevarse a cabo de la manera menos lesiva posible. En todo caso, lo que no resulta admisible es optar por la anonimización para evitar pedir el consentimiento incluso cuando existe la posibilidad de contactar con el sujeto fuente ${ }^{91}$. Para evitar abusos, sería recomendable que se exigiera a los Co-

\footnotetext{
${ }^{87}$ No nos parece que tenga suficiente peso el argumento que ofrecen Gert HELGESSON/Joakim Dillner/Joyce CARLSON/Claus R. BARTRAm/Mats G. HANSSON, "Ethical framework for previously collected biobank samples", Nature Biotechnology, no 9 (2007), p. 974, para defender el uso identificado de las muestras biológicas. Según estos autores, sólo si éstas se utilizan de forma identificada puede evitarse la utilización repetida de muestras provenientes de un mismo sujeto.

${ }^{88}$ Cfr. art. 20.1 de la Constitución española.

${ }^{89} \mathrm{Cfr}$. art. 18.1 y 4 de la Constitución española.

${ }^{90}$ El art. 7.3 de la Ley Orgánica 15/1999, de 13 de diciembre, de Protección de Datos de Carácter Personal establece que "los datos de carácter personal que hagan referencia al origen racial, a la salud y a la vida sexual sólo podrán ser recabados, tratados y cedidos cuando, por razones de interés general, así lo disponga una ley o el afectado consienta expresamente". En definitiva, la LIB viene a cubrir el requisito de previsión legal exigido por la LO 15/1999 para tratar datos personales sin consentimiento del sujeto fuente. Hay que recordar que aunque el tratamiento de muestras biológicas no entra dentro del ámbito de aplicación de la LO 15/1999, si éstas están vinculadas a una persona identificada o identificable, la información que se obtenga de las mismas será información personal sometida a la misma.

${ }^{91}$ En este mismo sentido, Y. Joly/B.M. KNOPPERs/M.T. NGuYEN, "Stored tissue simples: through the confidentiality maze", The Pharmacogenomics Journal, n 5 (2005), p. 4, entienden que «la anonimización de los datos y las muestras no debe ser usado por los investigadores como una excusa para reducir los obstáculos éticos y legales, o para obviar el derecho de autodeterminación de los participantes».
} 
mités de Ética de la Investigación la elaboración de informes periódicos sobre los proyectos de investigación en los que han autorizado un uso de muestras sin consentimiento del sujeto fuente ${ }^{92}$.

Independientemente de lo anterior, esto es, aunque la LIB prevea la posibilidad de utilizar muestras biológicas sin el consentimiento del sujeto fuente, ello no es óbice para que sea conveniente establecer mecanismos de información que permitan conocer a los ciudadanos que esta circunstancia podría llegar a producirse. Esto es importante pues es muy probable que, en la práctica diaria, se sigan almacenando muestras biológicas procedentes de procesos asistenciales sin abordar en el momento de su obtención la cuestión de su posible uso futuro con fines de investigación biomédica. Por ello, sería conveniente que las autoridades sanitarias emprendieran una campaña informativa a través de carteles o folletos, que permitan a los ciudadanos conocer sus derechos en relación con su material biológico, y donde se recoja de forma clara esta eventualidad legal. Se este modo, los pacientes podrán manifestar su voluntad contraria a que sus muestras obtenidas con fines diagnósticos sean utilizadas en un futuro sin su consentimiento (o en todo caso) con fines de investigación biomédica. Esta voluntad debería quedar recogida en la historía clínica del paciente y ser, en todo caso, respetada.

Para finalizar, aun queda por analizar una cuestión de enorme trascedencia práctica. Hasta ahora hemos comprobado que la LIB permite en casos excepcionales, y bajo ciertas condiciones, la utilización de muestras biológicas sin consentimiento del sujeto fuente. Ahora bien, esta previsión no alcanza a la información sanitaria de dichos sujetos. Para saber hasta qué punto es posible utilizar esas muestras biológicas junto con información del sujeto fuente hay que tener en consideraciones diversas disposiciones contenidas en la LOPD, la LAP y la propia LIB.

Así, el art. 5.2 LIB establece que "la cesión de datos de carácter personal a terceros ajenos a la actuación médico-asistencial o a una investigación biomédica, requerirá el consentimiento expreso y escrito del interesado (...). Y el apartado 3 de este mismo precepto añade que "se prohíbe la utilización de datos relativos a la salud de las personas con fines distintos a aquéllos para los que se prestó el consentimiento". Por otro lado, debemos recordar que la disposición final segunda de la LIB dispone que en lo no previsto en esta Ley serán de aplicación la LAP y la LOPD.

$\mathrm{El}$ art. 11.1. LOPD señala que "los datos de carácter personal objeto del tratamiento sólo podrán ser comunicados a un tercero para el cumplimiento de fines directamente relacionados con las funciones legítimas del cedente y del cesionario con el previo consentimiento del interesado". Del mismo modo, el art. 7.3 LOPD dispone que "los datos de carácter personal que hagan referencia al

${ }^{92}$ Cfr. Don Chalmers, "Ethical Principles for Research Governance of Biobanks", Journal of International Biotechnology Law, $\mathrm{n}^{\circ} 3$ (2006), pp. 227 y s. 
origen racial, a la salud y a la vida sexual sólo podrán ser recabados, tratados y cedidos cuando, por razones de interés general, así lo disponga una ley o el afectado consienta expresamente". Se requiere, por lo tanto, una Ley que prevea la posibilidad de tratar datos médicos sin consentimiento del sujeto fuente.

A este respecto, la propia LOPD recoge algunas excepciones. Así, en su art. 11.2 señala que "el consentimiento (...) no será preciso: f) Cuando la cesión de datos de carácter personal relativos a la salud sea necesaria para solucionar una urgencia que requiera acceder a un fichero o para realizar los estudios epidemiológicos en los términos establecidos en la legislación sobre sanidad estatal o autonómica".

Más claramente, según el art. 16.3 LAP, “el acceso a la historia clínica con fines (...) de investigación (...) se rige por lo dispuesto en la Ley Orgánica 15/1999, de Protección de Datos de Carácter Personal, y en la Ley 14/1986, General de Sanidad, y demás normas de aplicación en cada caso. El acceso a la historia clínica con estos fines obliga a preservar los datos de identificación personal del paciente, separados de los de carácter clínico-asistencial, de manera que como regla general quede asegurado el anonimato, salvo que el propio paciente haya dado su consentimiento para no separarlos (...)". Y en este mismo sentido, pero en relación con los datos genética, el art. 50.2 LIB establece que "los datos genéticos de carácter personal sólo podrán ser utilizados con fines (...) de investigación (...) cuando el sujeto interesado haya prestado expresamente su consentimiento, o cuando dichos datos hayan sido previamente anonimizados".

Por lo tanto, según se desprende de la normativa aplicable, la utilización de datos médicos de un sujeto con fines de investigación únicamente será posible si existe una razón de interés general (por ejemplo, existe una proyecto de investigación aprobado por el correspondiente Comité de Ética de la Investigación que requiere de dichos datos), y además: a) el sujeto titular de los datos lo autoriza; o b) si no es posible recabar dicho consentimiento, los datos se anonimizan ${ }^{93}$.

${ }^{93}$ Cfr. Carlos M. Romeo CASABona/Aitziber Emaldi Cirión/ Leire Escajedo SAn EPIFANio/Pilar Nicolás JimÉnez/Sergio Romeo MalandA/Asier URruela Mora, La Ética y el Derecho ante la biomedicina del futuro, Universidad de Deusto, Bilbao, 2006, pp. 117 y s.; Pilar NiCOLÁs JimÉNEZ, La protección jurídica de los datos genéticos de carácter personal, Cátedra Interuniversitaria de Derecho y Genoma Humano-Comares, Bilbao-Granada, 2006, p. 208 y ss.; Andrés Domínguez Luelmo, Derecho sanitario y responsabilidad médica, Editorial Lex Nova, Valladolid, 2003, pp. 445 y ss.

Ciertamente, el art. 50.3 LIB prevé la posibilidad de utilizar datos genéticos codificados sin el consentimiento del sujeto fuente en ciertos casos y bajo determinados requisitos. Según este precepto, "en casos excepcionales y de interés sanitario general, la autoridad competente, previo informe favorable de la autoridad en materia de protección de datos, podrá autorizar la utilización de datos genéticos codificados, siempre asegurando que no puedan relacionarse o asociarse con el sujeto fuente por parte de terceros". Sin embargo, no parece que la utilización de esta información en una investigación biomédica se acomode a los presupuestos de excepcionalidad e interés sanitario que exige esta disposición. 
En definitiva, cuando se autorice la utilización de muestras biológicas sin el consentimiento del sujeto fuente, podrán obtenerse nuevos datos, los cuales deberán conservarse adecuadamente, protegiendo la confidencialidad de los mismos (la LIB sirve de título legal habilitante para dicho tratamiento). Pero no se podrán incorporar datos médicos existentes con anterioridad sin el consentimiento del sujeto fuente ${ }^{94}$, a menos que las muestras biológicas estén anonimizadas. Es decir, si las muestras biológicas no han sido previamente anonimizadas, la vinculación a las mismas de información sanitaria será información de un sujeto identificado o identificable, lo cual es contrario a lo dispuesto en LAP y en la LIB. Si por el contrario, las muestras biológicas se utilizan de forma anonimizada, entonces la información que se vincule a las mismas ya no estaría referida a un sujeto identificado o identificable, en cuyo caso sí que podría asociarse a las muestras biológicas información procedente de la historia clínica del mismo, incluso sin su autorización.

\subsection{Circulación internacional de muestras biológicas}

De acuerdo con el art. 18 de la Declaración Internacional de la UNESCO sobre los Datos Genéticos Humanos, de 16 de octubre de 2003, "los Estados deberían regular la circulación transfronteriza de datos genéticos humanos, datos proteómicos humanos y muestras biológicas para fomentar la cooperación médica y científica internacional y garantizar un acceso equitativo a esos datos (...)". De manera similar, la Recomendación del Consejo de Europa 4 (2006) on research on biological materials of human origin establece en su art. 16 que "los materiales biológicos y los datos personales asociados a los mismos únicamente debería sen cedidos a otro estado si ese estado asegura un nivel de protección adecuado" 95 .

La LIB se ocupa de esta cuestión en su art. 11, según el cual, "[I] La entrada y salida intracomunitaria y extracomunitaria de muestras biológicas de origen humano con los fines de investigación biomédica a los que se refiere esta Ley se regirán por las disposiciones que se establezcan reglamentaria-

${ }^{94}$ En el caso de muestras biológicas obtenidas con posterioridad a la entrada en vigor de la LIB, su utilización únicamente se podrá llevar a cabo, como hemos visto, por la misma institución que solicitó el consentimiento para la obtención de las muestras. Esa institución (por ejemplo, un centro hospitalario) puede ser depositaria de la historia clínica del paciente-sujeto fuente. Sin embargo, cuando esos datos van a ser utilizados con fines distintos a aquéllos para los que se recogieron, aunque sea por personal de la misma institución, estamos ante una cesión de datos de carácter personal, y por lo tanto serán de aplicación las reglas aquí expuestas.

${ }^{95}$ En este mismo sentido, Medical Research Council, Human Tissue and biological samples for use in research. Operational and ethical guidelines, 2001, p. 14. 
mente $^{96}$. [II] Cuando se trate de de muestras biológicas procedentes de biobancos se observarán, además, las condiciones de cesión y seguridad que se establecen en el Título V de la presente Ley"97.

Este intercambio de muestras biológicas no será excepcional, pues hay que tener en cuenta que debido a la enorme variabilidad del medio, estilos de vida y disposiciones genéticas en diferentes lugares y en diferentes grupos étnicos, es necesario realizar una aproximación orientada globalmente en este tipo de investigación. Por ello, se precisa la colaboración entre biobancos. Sin embargo, es muy probable que surjan obstáculos en dicha cooperación en la investigación, algunos de los cuales serán los siguientes: a) gran parte de los biobancos son una mezcla de biobancos de una específica enfermedad y biobancos de población general, pero no se ha establecido una conexión entre ellos; b) muchos biobancos forman parte de un determinado centro o institución (por ejemplo, un hospital), por lo que no existe una información sobre su contenido. De ahí que muchos biobancos no sean accesibles; c) los sistemas de almacenamiento del material puede variar de un biobanco a otro (bloques de parafina, congelación, etc.); d) esa diferencia de sistema también supone una diferencia en la calidad del archivo, de tal forma que en ciertos casos los materiales almacenados pueden resultar dañados; e) puede haber diferentes maneras de apreciar el valor del consentimiento del sujeto fuente, por lo que es posible que se planteen ciertos conflictos éticos (por ejemplo, un biobanco se compone de muestras sin que los sujetos de los que provienen hubieran

\footnotetext{
${ }^{96}$ Actualmente, existe una norma reglamentaria. El Real Decreto 65/2006, de 30 de enero,
} por el que se establecen requisitos para la importación y exportación de muestras biológicas especifica las condiciones para la importación y exportación de muestras de sustancias biológicas y establece un sistema de registro voluntario que permite su importación y exportación continua. Sin embargo, este Real Decreto únicamente es de aplicación, tal y como establece su art. 1, a "la importación y exportación de muestras biológicas para el diagnóstico o la investigación en seres humanos (...)”. Por lo tanto, no es aplicable a la investigación con muestras biológicas in vitro.

Según esta Disposición final tercera de la LIB, "se faculta al Gobierno para dictar cuantas disposiciones resulten necesarias para el desarrollo y ejecución de esta ley, y en particular para establecer: a) Las normas de intercambio y circulación, interna, intracomunitaria y extracomunitaria, de material biológico de origen humano con fines de investigación (...)".

${ }^{97}$ Vid. un análisis más detallado de esta problemática, GRUPO PARA EL Uso DE MUESTRAS BiológiCAS PARA INVESTIGACIÓN BIOMÉDICA, Guía práctica para la utilización de muestras biológicas en investigación biomédica, Instituto Roche, Madrid, 2006, pp. 79 y ss.

Para el Medical Research Council, Human Tissue and biological samples for use in research. Operational and ethical guidelines, 2001, p. 26, así como para la ITALIAN SOCIETY OF Human Genetics, Guidelines for Genetic Biobanks, 2004, p. 12, cuando se quieran utilizar muestras obtenidas en terceros países, deberá acreditarse que en su obtención se han respetado también las garantías exigidas en el país de orígen. Cfr. igualmente, Don CHALMERs, "Ethical Principles for Research Governance of Biobanks", Journal of International Biotechnology Law, $\mathrm{n}^{\circ} 3$ (2006), pp. 229 y s. 
dado su consentimiento) ${ }^{98}$; f) la información que se ha obtenido y que está unida a la muestra puede no ofrecer todo el interés que se requiere por todos los investigadores; g) los registros están muchas veces en lenguas propias del país, y no existe traducción; h) las reglas de acceso a dicho material varía enormemente de un país a otro y de un biobanco a otro.

\section{El tratamiento de muestras biológicas en estudios de diversidad genética}

El art. 58.6 LIB señala que "en los estudios de diversidad genética se respetarán siempre las tradiciones locales y étnicas, evitando en todo caso prácticas de estigmatización y discriminación". Este precepto está haciendo referencia a los análisis genético-poblacionales. Por tal se entiende toda "investigación que tiene por objeto entender la naturaleza y magnitud de las variaciones genéticas dentro de una población o entre individuos de un mismo grupo o de grupos distintos" [art. 3.b) LIB].

La genética de poblaciones es aquella parte de la genética que estudia la distribución de los genes en las poblaciones y de cómo las frecuencias de los genes y de los genotipos cambian o se mantienen a lo largo del tiempo. Las frecuencias génicas y genotípicas son esenciales en muchas formas de análisis genético y tienen una particular importancia en los cálculos de los riesgos genéticos. De esta manera, para realizar un diagnóstico clínico correcto genéticamente, así como para un estudio de consejo genético, es importante conocer el origen geográfico y étnico de las familias que se están estudiando o si hay una historia familiar de consanguinidad. En los estudios genéticos, más que en cualquier otra especialidad médica, el paciente es un reflejo de la población a la que pertenece ${ }^{99}$.

Los estudios de diversidad genética pueden ser de muy diversa naturaleza, y pueden llevarse a cabo sobre grupos de población muy variados, no siempre con una connotación étnica. Así, este tipo de estudios son de gran relevancia en genética forense ${ }^{100}$, en investigaciones de carácter antropológico

\footnotetext{
${ }^{98}$ Bernice S. ElgER/Arthur L. CAPLAN, "Consent and anonymization in research involving biobanks", EMBO Reports, $\mathrm{n}^{\circ} 7$ (2006), p. 662, aluden a la enorme variedad de regulaciones relativas a los biobancos y cómo ello supone una evidente limitación a la colaboración entre los mismos.

${ }^{99}$ Vid. José Aurelio CASTRO OCÓN , "Enfermedades genéticas: una perspectiva poblacional", El médico interactivo. Diario electrónico de sanidad, publicación on-line: http://www.medynet.com/elmedico/informes/informe/enfgeneticas.htm (última consulta: 13 de abril de 2011).

${ }^{100}$ Para calcular la probabilidad de paternidad se tiene en cuenta, por un lado, la probabilidad que tiene el presunto padre de transmitir un marcador que está presente en él y en el niño que le reclama la paternidad, y por otro, la frecuencia del alelo en la población general o en la que se tome como referencia. Por ello, es necesario conocer la frecuencia con que los fenotipos (o variaciones) de los marcadores se distribuyen, o aparecen en la población de referencia. Esto puede comprenderse fácilmente cuando el fenotipo de un marcador presente
} 
sobre origen y evolución de la especie humana ${ }^{101}$ o relativas a los flujos migratorios, etc. Pero los estudios de diversidad genética también resultan trascendentales en investigación biomédica, si bien es cierto que algunas de estas investigaciones han resultado ciertamente controvertidas. Así, desde hace un par de décadas muchos investigadores se han lanzado a la búsqueda de genes humanos con características especiales, fundamentalmente de poblaciones indígenas, discapacitados y grupos geográficamente aislados, para descubrir diferencias mínimas en sus genomas que pudieran indicar tendencias a resistir (o ser más propensos) a ciertas enfermedades. Lejos de ser proyectos altruistas para atender los problemas de salud de esos grupos, la realidad ha demostrado que quienes tienen la tecnología y medios para usar esta información son poderosas trasnacionales, farmacéuticas o relacionadas con ese campo, que esperan encontrar nuevos medicamentos y únicamente actúan movidos por un ánimo personal de lucro. De hecho, muchos de los productos resultantes de tales investigaciones no tienen carácter curativo, sino que son revolucionarios productos de estética (belleza, pérdida de peso, etc.) dirigidos a la población sana de las sociedades occidentales.

Muchos de estos estudios se enmarcan dentro del Proyecto Genoma Humano sobre Diversidad, iniciado a principios de los años 90, cuya finalidad es estudiar la riqueza genética de la totalidad de la especie humana ${ }^{102}$, viéndose involucrados grupos indígenas considerados en peligro de extinción.

El Proyecto Genoma Humano sobre Diversidad pretendía conservar el material genético para la investigación antes de que desaparecieran. Sin embargo, las comunidades indigenas se han opuesto a dicho proyecto y han mostrado publicamente su indignación por la obtención y tratamiento del material biológico, así como por los métodos empleados en dicho proceso, los cuales no siempre han sido del todo correctos y no han garantizado la validez del

en el niño y en el padre presunto es un fenotipo raro en la población de referencia (está presente en un escaso número de individuos de esta población), la probabilidad de que sea ese hombre el que se lo ha transmitido al niño sea mayor que si se tratara de un fenotipo que está presente en un amplio número de individuos de la población, en cuyo caso son muchos los que han podido transmitirlo. V. Carlos María Romeo Casabona/Sergio Romeo Malanda, Los identificadores del ADN en el Sistema de Justicia Penal, Thomson-Aranzadi, Cizur Menor, 2010, pp. 37 y ss.

${ }^{101}$ Vid. Rosario CALDERÓN, "El Proyecto Genoma Humano sobre Diversidad: aspectos éticos", Revista de Derecho y Genoma Humano, no 4 (1996), pp. 123 y ss.

${ }^{102}$ Cfr. Rosario CAlDERón, "El Proyecto Genoma Humano sobre Diversidad: aspectos éticos", Revista de Derecho y Genoma Humano, no 4 (1996), pp. 121 y ss; John I. FLEMING, "La ética y el Proyecto Genoma Humano sobre Diversidad", Revista de Derecho y Genoma Humano, no 4 (1996), p. 160; Antonia V. Herzog/Mark S. Frankel, "A model ethical protocol as a guidance document for human genome diversity research", Revista de Derecho y Genoma Humano, no 10 (1999), p. 22; Michael Dodson, "Human Genetics: control of research and sharing of benefits", Australian Aboriginal Studies, $\mathrm{n}^{\circ} 1$ y 2 (2000), p. 56. 
consentimiento, por ausencia de una información previa adecuada o por la promesa de remuneraciones que incidían en la libertad del otorgante ${ }^{103}$. A este respecto, La Declaración de los pueblos indígenas del Hemisferio Occidental (Phoenix, EE.UU.), de 19 de febrero de 1995, en relación con el Proyecto de Diversidad del Genoma Humano, rechaza "la participación o permitir la apropiación o la extracción mediante proyectos científicos externos de cualesquiera materiales genéticos" y exige "al Proyecto de Diversidad del Genoma Humano y cualquier otro proyecto similar que cese en sus intentos de inducir o forzar la participación en sus proyectos, mediante promesas de beneficios y ganancias financieras con vistas a obtener así el consentimiento la participación de los pueblos indígenas". En el mismo sentido, La Declaración de Ukupseni (Kuna Yala, Panamá), de 13 de noviembre de 1997, sobre el Proyecto de Diversidad del Genoma Humano, señala que "en el proceso de recolección genética basado en los engaños y el aprovechamiento de la marginalidad y pobreza, se atropellan los derechos humanos fundamentales, y los derechos colectivos", así como que tales "investigaciones son un acto de piratería, robo y constituyen una agresión a los pueblos indígenas". Por ello exigen "la suspensión inmediata de estas actividades y la devolución completa de las colecciones genéticas almacenadas: material genético original, las líneas celulares aisladas y los datos obtenidos de estas investigaciones".

En muchas ocasiones, este tipo de estudios genético-poblacionales no requerirán el uso de muestras asociadas a sujetos determinados, pues no es tan importante la identidad del individuo como su pertenencia a un determinado grupo poblacional. Ahora bien, hay que tener en cuenta que en estos casos, la muestra biológica puede ser anónima en relación con la identidad de un individuo en concreto, pero no con respecto a una clase de individuos que formen parte de un grupo o comunidad, de tal forma que los resultados del estudio

${ }^{103}$ Vid. Antonia V. Herzog/Mark S. FrANKEL, “A model ethical protocol as a guidance document for human genome diversity research", Revista de Derecho y Genoma Humano, $\mathrm{n}^{\circ}$ 10 (1999), pp. 23 y s. Por ello, los proyectos dirigidos a la obtención de muestra biológicas (fundamentalmente sangre) de poblaciones indígenas (que se popularizaron a mediados de los años noventa) recibieron el calificativo de proyectos vampiro (Vampire Project). También se habla de helicopter genetics, para describir el proceso en el que un grupo de investigación se desplaza (en helicóptero o avioneta) a una remota localización donde una condición genética es prevalente a fin de obtener historías clínicas, sangre de los habitantes del lugar, y volver a su laboratorio de origen para analizar las muestras, sin que se vuelva a saber nunca más de ellos. Cfr. Dianne NICOL, "Public Trust, Intellectual Property and Human Genetic Databases: The Need to Take Benedit Sharing Seriously", Journal of Internacional Biotechnology Law, $\mathrm{n}^{\circ} 3$ (2006), p. 93.

De hecho, algunas disputas por el uso de las muestras biológicas han acabado en los tribunales. Este es el caso de la demanda interpuesta por la tribu Havasupai (Arizona, Estados Unidos de América) contra la Universidad del Estado de Arizona, resuelta en el año 2004. Vid. sobre este particular, Larry I. PALMER, "Should Liability Play a Role in Social Control of Biobanks", The Journal of Law, Medicine \& Ethics, $\mathrm{n}^{\circ} 1$ (2005), pp. 75 y ss. 
pueden suponer un riesgo para individuos pertenecientes a dichos grupos, los cuales podrían llegar a sufrir algún tipo de discriminación o estigmatización ${ }^{104}$. Por esta razón, los Comités de Ética de la Investigación deberán analizar muy atentamente los protocolos de investigación en los que se prevé utilizar muestras anónimas con el fin de salvaguardar los derechos de grupos y comunidades, especialmente cuando se trate de estudios de diversidad genética.

Por otra parte, como hemos dicho anteriormente, en ocasiones este tipo de investigaciones puede involucrar a grupos poblacionales con tradiciones muy arraigadas o con una conciencia de comunidad muy acentuada. Ello debe ser tenido muy en cuenta, por ejemplo, a la hora de transmitir la información y solicitar el consentimiento para participar en el estudio. A este respecto, hay que tratar de conciliar dos aspectos: por un lado, esa idea de colectividad, de tal modo que habría que dar cabida de alguna manera a la defensa de los posibles intereses colectivos, cuando fueran identificables ${ }^{105}$; y por otra parte, que el titular de cada muestra biológica y de los datos obtenidos de la misma es en todo caso en sujeto fuente, por lo que debe exigirse el consentimiento individualizado de cada participante. A tal fin, se ha propuesto consultar a los representantes del grupo investigado, incluso requiriendo el consentimiento de la población a través de sus autoridades culturales, cuando existan ${ }^{106}$, de tal

${ }^{104}$ M. DeschêNES/G. CARDinAL/B.M. KnOPERs/K.C. Glass, "Human genetic research, DNA banking and consent: a question of 'form'?”, Clinical Genetics, $\mathrm{n}^{\circ} 59$ (2001), pp. 226 y s.; Garrath WiLliams/Doris Schroeder, "Human Genetic banking: altruism, benefit and consent", New Genetics and Society, n ${ }^{\circ} 1$ (2004), p. 96; German NATIONAL Ethics Council, Biobanks for Research, 2004, pp. 69 y s.; Mark A. RoTHSTEIN, "Expanding the Ethical Analysis of Biobanks", The Journal of Law, Medicine \& Ethics, n 1 (2005), p. 90; Bernice S. ELGER/Arthur L. CAPLAN, "Consent and anonymization in research involving biobanks", EMBO Reports, $\mathrm{n}^{\circ} 7$ (2006), p. 664.

${ }^{105}$ Para Pilar Nicolás JimÉNEZ, La protección jurídica de los datos genéticos de carácter personal, Cátedra Interuniversitaria de Derecho y Genoma Humano-Comares, Bilbao-Granada, 2006, pp. 359 y s., para ello «será preciso que se trate de una comunidad genéticamente homogénea y que cuente con autoridades reconocidas y respetadas por sus miembros, con ciertas facultades que las revistan de un poder de interlocución y representación válido. La integración de estas autoridades en el proceso de obtención del consentimiento individual puede ser adecuada para garantizar que éste se emita válidamente aunque pueda interferir en la decisión».

${ }_{106}$ Antonia V. Herzog/Mark S. Frankel, "A model ethical protocol as a guidance document for human genome diversity research", Revista de Derecho y Genoma Humano, $\mathrm{n}^{\circ} 10$ (1999), pp. 25 y 29; Michael DodSON, "Human Genetics: control of research and sharing of benefits", Australian Aboriginal Studies, n 1 y 2 (2000), pp. 58 y s.; EUROPEAN SOCIETY OF HuMAN GENETICS, Recommedations on data storage and DNA banking for biomedical research: technical, social and ethical issues, 2001, Recomendación 15; Ruth CHADWICK/Kåre BERG, "Solidarity and equity: new ethical framework for genetic databases", Nature Reviews Genetics, nº 2 (2001), p. 319; Béatrice GodARD/Jörg SCHMIDTKE/Jean-Jacques CASSIMAN/Ségolène AYMÉ, "Data storage and DNA banking for biomedical research: informed consent, confidentiality, quality issues, ownership, return of benefits. A profesional perspectiva", $E u$ ropean Journal of Human Genetics, $\mathrm{n}^{\circ} 11$ (2003), p. 95; GERMAN NATIONAL ETHICS COuNCIL, Biobanks for Research, 2004, p. 71. 
modo que un determinado estudio genético poblacional no podría llevarse a cabo cuando el representante de un grupo se oponga expresamente ${ }^{107}$. Sin embargo, no se debe desconocer que el consentimiento para la investigación corresponde individualmente al sujeto que participa en ella. Por esta razón, otros autores entienden que el modo más adecuado de responder a las reivindicaciones de estos grupos y de armonizarlas con los derechos individuales, sería otorgando a dicha autoridad un papel de interlocución y mediación entre los investigadores y los individuos integrantes del grupo ${ }^{108}$. Finalmente el consentimiento será individual, pero se habrá asegurado que la información sobre las circunstancias de la investigación es adecuada a sus caracteristicas personales (por ejemplo, utilizando sus idiomas locales).

La mencionada Declaración de Ukupseni, de 13 de noviembre de 1997, sobre el Proyecto de Diversidad del Genoma Humano, señala a este respecto lo siguiente: "Para nosotros el uso del llamado "consentimiento individual" constituye un atropello a nuestras culturas y el desconocimiento de nuestros derechos colectivos".

${ }^{107} \mathrm{~A}$ fin de proporcionar una mayor protección a estas poblaciones, se ha propuesto también la conveniencia, en determinados casos, de solicitar la autorización del gobierno (Vid. el Editorial "El debate ético y jurídico en torno al Proyecto Genoma Humano sobre Diversidad ¿son conciliables todas las perspectivas?", Revista de Derecho y Genoma Humano, $\mathrm{n}^{\circ} 4$ (1996), p. 14), o la posibilidad de crear un Comité de Ética ad hoc encargado de velar por los intereses de las comunidades indígenas [Michael Dodson, "Human Genetics: control of research and sharing of benefits", Australian Aboriginal Studies, $\mathrm{n}^{\circ} 1$ y 2 (2000), p. 61].

${ }^{108}$ En este sentido, Italian Society Of Human Genetics, Guidelines for Genetic Biobanks, 2004, p. 8; Pilar Nicolás JimÉnEZ, La protección jurídica de los datos genéticos de carácter personal, Cátedra Interuniversitaria de Derecho y Genoma Humano-Comares, Bilbao-Granada, 2006, p. 360. 